\title{
The impact of Organic Anion-Transporting Polypeptides (OATPs) on disposition and toxicity of antitumor drugs: Insights from knockout and humanized mice
}

\author{
Selvi Durmus ${ }^{\mathrm{a}, 1}$, Stéphanie van Hoppe ${ }^{\mathrm{b}, 1}$, Alfred H. Schinkel ${ }^{\mathrm{b}, *}$ \\ a Bilkent University, Department of Molecular Biology and Genetics, 06800 Bilkent, Ankara, Turkey \\ ${ }^{\mathrm{b}}$ The Netherlands Cancer Institute, Division of Molecular Oncology, Plesmanlaan 121, 1066 CX Amsterdam, The Netherlands
}

\section{A R T I C L E I N F O}

\section{Article history:}

Received 6 February 2016

Received in revised form 7 May 2016

Accepted 17 June 2016

\section{Keywords:}

OATP1A/1B transporters

OATP1B1

OATP1B3

Drug disposition

Hepatic uptake

Drug-drug interactions

\begin{abstract}
A B S T R A C T
It is now widely accepted that organic anion-transporting polypeptides (OATPs), especially members of the OATP1A/1B family, can have a major impact on the disposition and elimination of a variety of endogenous molecules and drugs. Owing to their prominent expression in the sinusoidal plasma membrane of hepatocytes, OATP1B1 and OATP1B3 play key roles in the hepatic uptake and plasma clearance of a multitude of structurally diverse anti-cancer and other drugs. Here, we present a thorough assessment of the currently available OATP1A and OATP1B knockout and transgenic mouse models as key tools to study OATP functions in vivo. We discuss recent studies using these models demonstrating the importance of OATPs, primarily in the plasma and hepatic clearance of anticancer drugs such as taxanes, irinotecan/SN-38, methotrexate, doxorubicin, and platinum compounds. We further discuss recent work on OATP-mediated drug-drug interactions in these mouse models, as well as on the role of OATP1A/1B proteins in the phenomenon of hepatocyte hopping, an efficient and flexible way of liver detoxification for both endogenous and exogenous substrates. Interestingly, glucuronide conjugates of both the heme breakdown product bilirubin and the protein tyrosine kinase-targeted anticancer drug sorafenib are strongly affected by this process. The clinical relevance of variation in OATP1A/1B activity in patients has been previously revealed by the effects of polymorphic variants and drug-drug interactions on drug toxicity. The development of in vivo tools to study OATP1A/1B functions has greatly advanced our mechanistic understanding of their functional role in drug pharmacokinetics, and their implications for therapeutic efficacy and toxic side effects of anticancer and other drug treatments.
\end{abstract}

(C) 2016 Elsevier Ltd. All rights reserved.

\section{Introduction to OATP1A/1B transporters and genetically modified mouse models to study their functions}

\subsection{Properties of OATP1A/1B transporters}

Organic anion-transporting polypeptide (OATP) uptake transporters can play a major role in the uptake of numerous compounds, including many anticancer drugs, into cells and organs. Positioned

Abbreviations: ABC, ATP-binding cassette; AUC, area under the concentrationtime curve; DDI, drug-drug interactions; E2G, estradiol 17 $\beta$-D-glucuronide; i.v., intravenous; OATP, organic anion-transporting polypeptide; TKI, tyrosine kinase inhibitor; UGT1A1, UDP-glucuronosyltransferase 1A1.

* Corresponding author.

E-mail address: a.schinkel@nki.nl (A.H. Schinkel).

1 These two authors contributed equally to this paper. in the plasma membrane, these multispanning transmembrane proteins can mediate the uptake of a structurally highly diverse range of substrates into the cell, by as yet incompletely resolved mechanisms. As a consequence, they can have a major impact on the pharmacokinetic disposition of transported drugs, determining their oral availability and plasma clearance, as well as their distribution to liver and other organs, and the main route(s) of elimination (for recent reviews see: Gong and Kim, 2013; Konig et al., 2013; Niemi et al., 2011; Shitara et al., 2013; Stieger and Hagenbuch, 2014). OATPs can therefore have a strong effect on the therapeutic efficacy, but also the toxic side effects of substrate drugs. Moreover, several OATPs are variably expressed in a range of human cancers. As this may obviously influence the effective intracellular exposure of the cancer cells to OATP substrate anticancer drugs, this can directly affect the therapy susceptibility of these cancers (for recent reviews see: Nakanishi and Tamai, 2014; Obaidat et al., 2012; Sissung et al., 2012; Thakkar et al., 2015). The activity of the human 
OATPs that are thought to be most important for the general pharmacokinetic behavior of drugs, OATP1A2, OATP1B1, and OATP1B3 (as well as possibly OATP2B1, but see below), can further vary dramatically because of genetic polymorphisms and mutations that affect drug transport, but also because of drug-drug interactions with a variety of co-administered drugs (e.g. Durmus et al., 2015; Franke et al., 2009; Gong and Kim, 2013; Konig et al., 2013; Niemi et al., 2011; Obaidat et al., 2012; Shitara et al., 2013; Stieger and Hagenbuch, 2014; van de Steeg et al., 2012).

Given their obvious medical importance, it is crucial to obtain clear insight into the in vivo pharmacological, toxicological, and physiological functions of the OATP proteins, especially those of the OATP1A/1B family. One way to achieve this goal is to generate and study mouse strains that have the mouse Oatp1a and Oatp $1 \mathrm{~b}$ genes knocked out, or that have replaced the mouse Oatp $1 \mathrm{a} / 1 \mathrm{~b}$ genes with one or more of their human analogues (although the formal gene name for the OATP-encoding genes is SLCO (for Solute Carrier of Organic Anions), for simplicity we will mostly use the OATP/Oatp nomenclature in this review). These mouse models can then be used to investigate the impact of the genetic modifications on the behavior of, amongst others, anticancer drugs. This review focuses on recent studies on such mouse strains and the insights obtained for a number of anticancer drugs. As some aspects have already been extensively reviewed previously (Iusuf et al., 2012b,c; Sprowl and Sparreboom, 2014; Tang et al., 2013), we will only briefly touch upon those.

\subsection{OATP1A/1B knockout and transgenic mouse strains characterized to date}

To date, most characterized knockout and transgenic mouse models concern members of the OATP1A and OATP1B subfamilies, as these are thought to be most relevant for overall pharmacokinetics in man. Some initial studies suggested that human OATP1A2 was expressed in the intestinal epithelium, which would potentially indicate an important role in drug absorption (Glaeser et al., 2007). However, many independent later studies could not corroborate these findings, and it is now probably safe to conclude that normally there is no substantial level of OATP1A2 present in the small or large intestine of humans (e.g. Drozdzik et al., 2014). On current data, OATP1A2 is substantially expressed in cholangiocytes lining the bile ducts in the liver, in the human blood-brain barrier, in apical membranes of kidney tubules, and in a variety of human tumors (van de Steeg et al., 2013 and references therein). In contrast to OATP1A2, human OATP1B1 and OATP1B3 are highly and primarily expressed in the basolateral (sinusoidal) membrane of human hepatocytes, where they can mediate the hepatic uptake of numerous substrate compounds (e.g. Nakanishi and Tamai, 2012). As these genes are also known to be substantially affected by genetic polymorphisms and mutations in humans (e.g. Niemi et al., 2011; van de Steeg et al., 2012), they have attracted most attention. The functionally related OATP2B1 protein is also a broad-specificity multidrug-uptake transporter, especially at lower $\mathrm{pH}$, and highly expressed in both intestine and the sinusoidal membrane of hepatocytes. It has therefore been suggested that it might also have considerable pharmacokinetic impact (Nakanishi and Tamai, 2012). However, to date no OATP2B1 mouse models have been published, so we will not further cover this transporter here.

A complication in studying mouse models for the OATP1A/1B transporters is that there are no straightforward orthologues between the individual mouse and human Oatp1a/1b and OATP1A/1B genes. As indicated in Fig. 1, there are no less than 4 different Oatp1a genes in the mouse, Oatp1a1, Oatp1a4, Oatp1a5 and Oatp1a6, in addition to 2 Oatp1a-like elements that may be pseudo-genes. This compares with the single OATP1A2 gene in
Table 1

Oatp1a/b knockout and transgenic mouse models described to date.

\begin{tabular}{|c|c|c|}
\hline Mouse models & Genetic background & Primary references \\
\hline Oatp1a1 knockout & $\mathrm{C} 57 \mathrm{Bl} / 6 \mathrm{~N}$ & (Gong et al., 2011) \\
\hline Oatp1a4 knockout & $\mathrm{C} 57 \mathrm{Bl} / 6 \mathrm{~N}$ & $\begin{array}{l}\text { (Gong et al., 2011; } \\
\text { Ose et al., 2010) }\end{array}$ \\
\hline Oatp1b2 knockout (variant 1) & C57BL/6 & (Lu et al., 2008) \\
\hline Oatp1b2 knockout (variant 2) & DBA1/lacJ & (Zaher et al., 2008) \\
\hline Oatp1a/1b knockout & FVB & $\begin{array}{l}\text { (van de Steeg et al., } \\
\text { 2010) }\end{array}$ \\
\hline $\begin{array}{l}\text { Humanized hepatic OATP1A2 } \\
\text { transgenic }\end{array}$ & FVB & $\begin{array}{l}\text { (van de Steeg et al., } \\
\text { 2013) }\end{array}$ \\
\hline $\begin{array}{l}\text { Humanized hepatic OATP1B1 } \\
\text { transgenic }\end{array}$ & FVB & $\begin{array}{l}\text { (van de Steeg et al., } \\
\text { 2009) }\end{array}$ \\
\hline $\begin{array}{l}\text { Humanized hepatic OATP1B3 } \\
\text { transgenic }\end{array}$ & FVB & $\begin{array}{l}\text { (van de Steeg et al., } \\
\text { 2013) }\end{array}$ \\
\hline $\begin{array}{l}\text { Humanized hepatic OATP1B1 } \\
\text { and OATP1B3 transgenic }\end{array}$ & FVB & $\begin{array}{l}\text { (Salphati et al., } \\
\text { 2014) }\end{array}$ \\
\hline
\end{tabular}

humans. On the other hand, the mouse has only one Oatp1b2 gene, contrasting with the two human OATP1B1 and OATP1B3 genes (Fig. 1). Although the mouse and human OATP1A proteins are obviously more similar to each other than to the mouse and human OATP1B proteins, and vice versa, the amino acid divergence within each subfamily is still considerable (as low as 67\% amino acid identity within the OATP1A subfamily, and $65 \%$ within the OATP1B subfamily). Consequently, with these broad-specificity multidrug transporters, no reliable statements can be made on overlapping substrates just based on amino acid similarity. As the tissue distribution is also not conserved between members of one subfamily (for instance, mouse Oatp1a1 and Oatp1a4 are present in the sinusoidal membrane of hepatocytes, whereas human OATP1A2 is not) it is clear that one cannot use single-gene mouse Oatp1a or Oatp1b knockout strains to make reliable predictions on the in vivo behavior of human OATP1A2, OATP1B1, or OATP1B3. This was an important motivation to generate a complete Oatp1a/1b knockout strain, and use it to specifically express human OATP1A2, OATP1B1, and OATP1B3 in this knockout background (van de Steeg et al., 2012, 2013, 2010).

Table 1 lists the various Oatp1a and Oatp1b knockout strains, and OATP1A/1B humanized strains that have been described so far. Oatp1a1 and Oatp1a4 knockout strains were described by Ose et al. (2010) and Gong et al. (2011). These mouse strains, originally made in 129/Ola ES cells by Deltagen, were backcrossed 10 times to a C57BL/6 background, and subsequent characterization of these lines was mainly done in this genetic background. A few independent Oatb1b2 knockout strains were generated. Lu et al. (2008) described the generation and initial characterization of an Oatp1b2 knockout strain generated in 129S1 ES cells, which was backcrossed for 7 generations to a C57BL/6 background. Independently, Zaher et al. (2008) generated Oatp1b2 knockout mice using DBA1/lacJ ES cells, which were further kept and characterized in a DBA1/lacj genetic background. Combined Oatp1a/1b knockout mice, covering all the mouse Oatp1a and Oatp1b genes, were generated in 129/Ola ES cells. Initial characterization of Oatp1a/1 $b^{-1-}$ mice was done in a mixed ( $\sim 50 \%) 129 /$ Ola and FVB genetic background (van de Steeg et al., 2010), but this strain was subsequently backcrossed for at least 7 generations to an FVB background, in which further characterization took place (van de Steeg et al., 2012). These FVB background Oatp $1 \mathrm{a} / 1 \mathrm{~b}^{-/-}$mice were then used to generate three different humanized mouse strains with predominant expression of human OATP1A2, OATP1B1, or OATP1B3 cDNA, respectively, in the liver parenchyme cells, again all in FVB background (van de Steeg et al., 2012, 2013). Moreover, a combined humanized OATP1B1/OATP1B3 strain was created by crossing the separate transgenic strains (Salphati et al., 2014). 

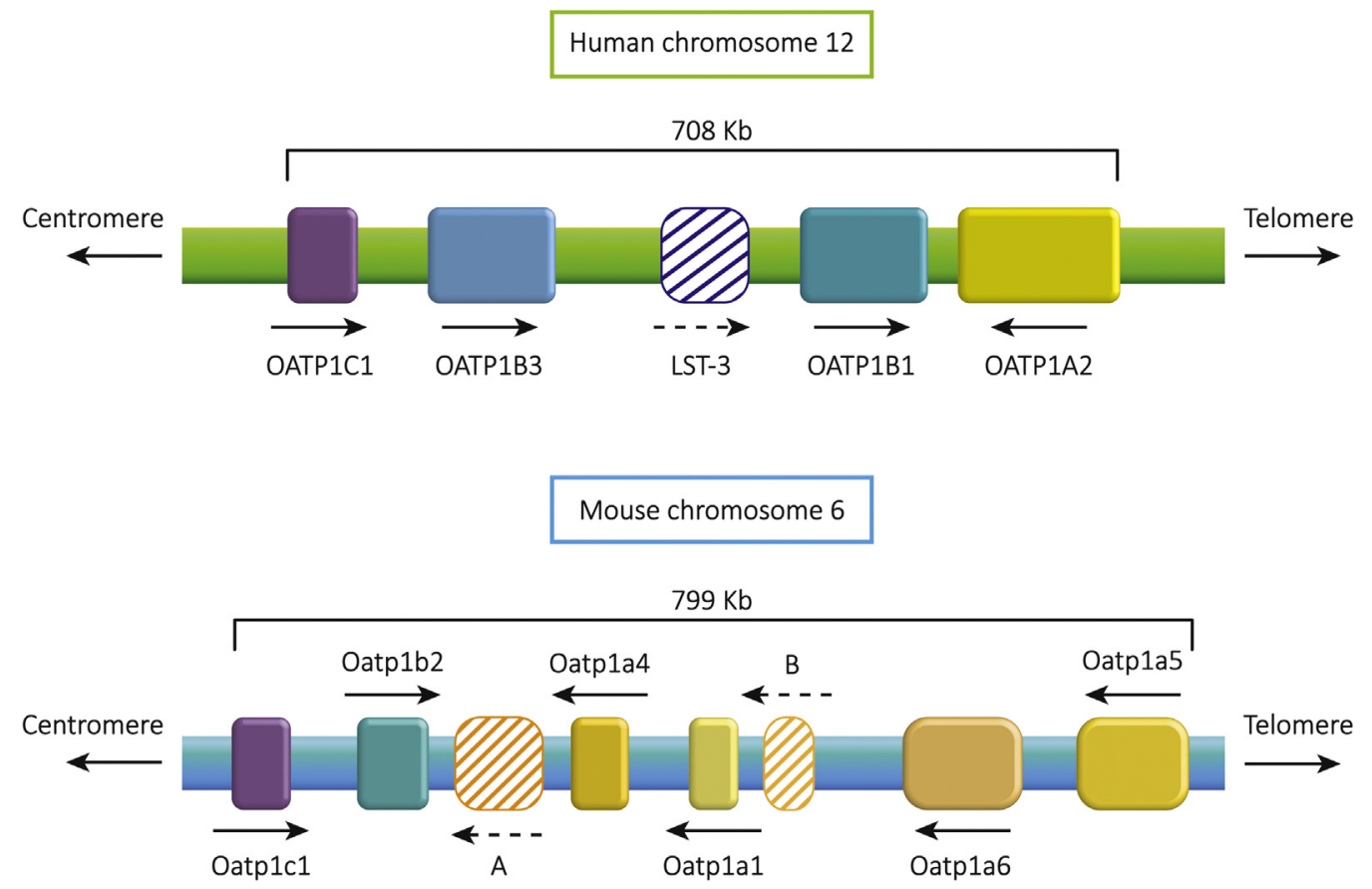

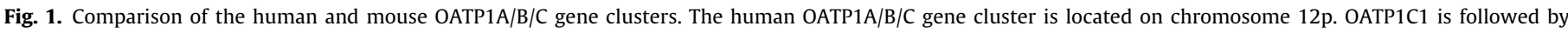

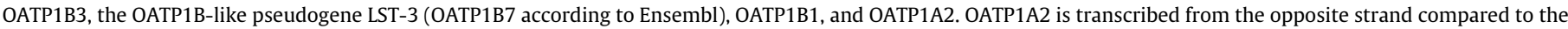

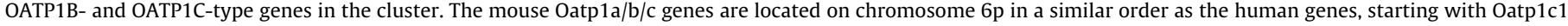

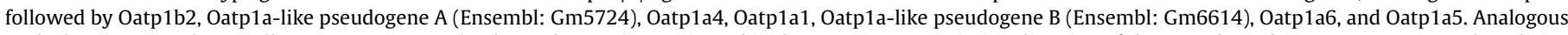

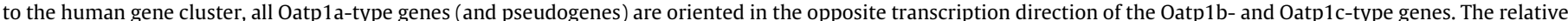

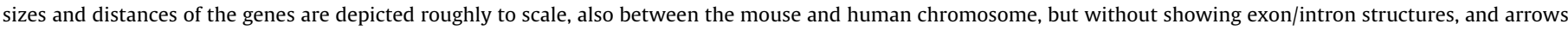

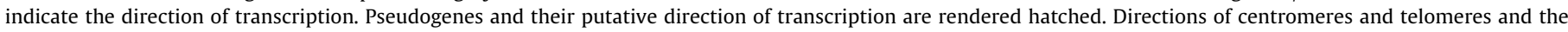
approximate size of the human and mouse gene clusters are indicated.

\subsection{Caveats in using OATP1A/1B genetically modified mouse models}

It should be noted that the genetic background strain may at times be important for the extent to which certain phenotypes are detectable in knockout and transgenic mice. Although this has not been systematically analyzed so far in the various Oatp knockout strains, we have observed modest physiological changes in Oatp1a/1 $\mathrm{b}^{-/-}$mice in mixed Ola/129/FVB background, which disappeared upon further backcrossing into an FVB background (unpublished data).

Also the environmental conditions (e.g., diet, bedding, intestinal microflora) may at times be important factors in the penetrance of certain phenotypes. For instance, we have observed that FVB background Oatp1a/1 $\mathrm{b}^{-1-}$ mice analyzed in our facility (The Netherlands Cancer Institute, NKI) had a marked induction of carboxylesterase genes relative to wild-type FVB mice (Iusuf et al., 2014). However, the very same strain of mice obtained by other groups through a commercial supplier (Taconic) did not show a difference in carboxylesterase expression with wild-type mice (Salphati et al., 2014). Further analysis suggested that this was because the wild-type FVB mice obtained from Taconic already had a much higher endogenous hepatic carboxylesterase expression compared to FVB mice kept at the NKI, most likely because of environmental differences. The Oatp1a/1b knockout from "Taconic" circumstances did not further increase carboxylesterase expression. Interestingly, humanizing the Oatp $1 \mathrm{a} / 1 \mathrm{~b}$ knockout mice with the OATP1B1 transgene did reverse the high carboxylesterase expression in both NKI and Taconic mice (Iusuf et al., 2014; Salphati et al., 2014), indicating that this could apparently overrule any environmental factors causing the different carboxylesterase expression in FVB wild-type mice. On the other hand, transgenic OATP1B3 could fully reverse the carboxylesterase overexpression in the NKI facility, but not elsewhere. This further supports that, whatever the factor(s) pushing up carboxylesterase expression in the Oatp1a/1 $\mathrm{b}^{-1-}$ (and FVB) mice, they were more prominent in the other facilities than in the NKI facility. It is important to keep such complications in mind when comparing the results in genetically modified mouse strains obtained by different groups. Moreover, as environmental conditions in mouse facilities cannot always be kept under complete control, it is also possible that shifts in phenotypes occur over time even within one facility.

Thirdly, also gender may substantially affect results obtained with Oatp1a/1b genetically modified mice. For instance, Oatp1a1, Oatp1a4, and Oatp1b2 are all substantially expressed in the basolateral (sinusoidal) membrane of the mouse liver. Judged by RNA level, Oatp1a1 is more abundant in male than in female liver (about 2-fold), and Oatp1a4 in female liver (also about 2-fold), whereas Oatp1b2 is similarly expressed in both genders (Cheng et al., 2005). This can directly affect whether certain pharmacokinetic effects can be detected in knockout strains. For instance, Gong et al. (2011) found that Oatp1a1 deficiency substantially reduced the clearance of the diagnostic dye dibromosulfophthalein in male mice, but not in female mice.

In some cases, authors have asserted that the knockout of mouse Oatp1b2, as the single mouse representative of the mammalian OATP1B subfamily (Fig. 1), might be more or less equivalent to the deficiency of OATP1B1 and OATP1B3 in humans (e.g., Zaher et al., 2008). However, for many OATP substrates this assumption clearly does not apply. In humans, OATP1B1 and OATP1B3 are the only members of the OATP1A/1B family that are present in the basolateral membrane of liver parenchyme cells, and thus involved in the uptake of substrates from blood into the liver. Human OATP1A2 is also expressed in the liver, but only found in the cholangiocytes, and therefore irrelevant for the direct uptake of compounds from blood into the liver. In contrast, in the mouse there are two OATP1A 
proteins that are substantially present in the sinusoidal membrane of liver parenchyme cells, Oatp1a1 and Oatp1a4. This means that for any substrate that is substantially transported by both Oatp1b2 and either or both of Oatp1a1 or Oatp1a4, results obtained in single Oatp1b2-1- mice may underestimate the effects of OATP1B1 and OATP1B3 deficiency in humans. A case in point is the role of OATP1B1 and OATP1B3 in the uptake of conjugated bilirubin. Whereas single Oatp $1 \mathrm{~b} 2^{-1-}$ mice showed only a marginal increase in plasma total and conjugated bilirubin levels (Lu et al., 2008; Zaher et al., 2008), in full Oatp1a/1 $b^{-1-}$ mice there was a pronounced increase in plasma bilirubin glucuronide levels (van de Steeg et al., 2010). The latter observation pointed to the prominent role that human OATP1B1 and OATP1B3 play in the reuptake of conjugated bilirubin in human liver, and provided the mechanistic explanation for the human Rotor syndrome caused by full OATP1B1 and OATP1B3 deficiency (van de Steeg et al., 2012). Clearly, the redundant role of Oatp1a1 and Oatp1a4 relative to Oatp1b2 in hepatic uptake of conjugated bilirubin in the mouse obscured the important contribution of the human OATP1B proteins in this process. Great care must therefore be taken when extrapolating from results in Oatp1b2-I- mice to the functional role of the human OATP1B1 and OATP1B3 proteins in liver. For pharmacokinetic studies, given the very substantial but incomplete and unpredictable overlap in substrate specificity between the various mouse and human OATP1A/1B transporters, every drug should be carefully assessed in its own right, and great caution should be used in extrapolating from results obtained in single knockout strains to the human situation.

Keeping these caveats in mind, in this review we will focus on recent studies performed with these mouse models for a range of anticancer drugs. Fig. 2 provides an overview of the structures of these drugs, also illustrating their structural diversity. The aim of such studies was to obtain basic insight into the handling of the anticancer drugs by OATP1A/1B proteins, in the hope that this knowledge may ultimately be used to improve current anticancer drug treatment regimens, by enhancing therapeutic efficacy of these drugs, reducing toxic side effects, and possibly both.

\section{Recent pharmacological and toxicity studies with OATP knockout and humanized mice}

\subsection{Taxanes}

The taxanes paclitaxel and docetaxel are cytotoxic anticancer drugs that bind to microtubules and disrupt their function by stabilizing GDP-bound tubulin, thus interfering with proper cell division. Paclitaxel and docetaxel are currently applied intravenously (i.v.) in the treatment of several types of cancer, such as non-small cell lung cancer, ovarian, breast, gastric, prostate, and head-and-neck cancer (Gligorov and Lotz, 2004; Koolen et al., 2010). Both paclitaxel and docetaxel are quite large, very hydrophobic, uncharged molecules (Fig. 2). It was therefore thought that they could pass cell membranes primarily by passive diffusion, so it was initially a bit of a surprise that these molecules were substantially taken up into cells by OATP1B1 and OATP1B3 in several (but not all, see also Section 4) in vitro expression systems (Baker et al., 2009; de Graan et al., 2012; Nieuweboer et al., 2014; Smith et al., 2006; Svoboda et al., 2011). To assess the possible in vivo relevance of this uptake transport, a number of studies with paclitaxel and docetaxel were performed in OATP/Oatp knockout and transgenic mice.

\subsubsection{Paclitaxel}

Van de Steeg et al. (2011) found that the paclitaxel plasma AUC was more than 2 -fold increased in Oatp $1 \mathrm{a} / 1 \mathrm{~b}^{-1-}$ relative to wildtype mice after i.v. administration at $10 \mathrm{mg} / \mathrm{kg}$. Conversely, the liver AUC was 2 -fold lower in the Oatp1a/1 $\mathrm{b}^{-1-}$ mice. Clear differences in plasma and liver paclitaxel concentrations were not yet apparent at $3.5 \mathrm{~min}$, but emerged from $7.5 \mathrm{~min}$ after administration. This suggests that the very early paclitaxel distribution, when plasma concentrations were very high $(>20 \mathrm{mg} / \mathrm{l})$, was not much dependent on Oatps. However, with plasma concentrations below $20 \mathrm{mg} / \mathrm{l}$, paclitaxel liver uptake and hence plasma clearance became strongly dependent on Oatp1a/1b transporters. This suggested that at plasma levels above $20 \mathrm{mg} / \mathrm{l}$ the sinusoidal Oatp1a/1b proteins were saturated, and other uptake processes, perhaps passive diffusion, dominated the liver uptake of paclitaxel. This was supported by limited paclitaxel distribution studies at a higher dosage $(50 \mathrm{mg} / \mathrm{kg})$, which yielded reduced differences between Oatp $1 \mathrm{a} / 1 \mathrm{~b}^{-1-}$ and wild-type mice in plasma concentration (1.7fold) and liver concentration (1.5-fold) $30 \mathrm{~min}$ after paclitaxel administration compared to the $10 \mathrm{mg} / \mathrm{kg}$ dose (1.9-fold and 2.2.fold, respectively). Overall, the data indicate a substantial role of hepatic sinusoidal Oatp1a/1b proteins in the clearance of paclitaxel from plasma, at plasma concentrations that can also occur in patients. Following high-dose paclitaxel chemotherapy, peak plasma concentrations range from 2 to $11 \mathrm{mg} / \mathrm{l}$ (Rowinsky and Donehower, 1995), i.e. well below the saturation level of the Oatp1a/1b proteins. A later, independent study by Nieuweboer et al. (2014) found quantitatively similar effects of a single Oatp1b2 knockout on the plasma AUC and liver accumulation of i.v. paclitaxel dosed at $5 \mathrm{mg} / \mathrm{kg}$ in mice. This could indicate that most of the effects on paclitaxel observed in the Oatp $1 \mathrm{a} / 1 \mathrm{~b}^{-1-}$ mice were primarily mediated by Oatp1b2 deficiency, although differences in genetic background strain (DBA/1lacJ vs. FVB), exact paclitaxel formulation used, laboratory and even period of experimentation, may all affect the detailed outcome of such studies (e.g. Nieuweboer et al., 2014; Sparreboom and Mathijssen, 2014).

In a follow-up study, the pharmacokinetics of paclitaxel was analyzed in "humanized" Oatp $1 \mathrm{a} / 1 \mathrm{~b}^{-1-}$ mice with transgenic expression of human OATP1B1, OATP1B3, or OATP1A2 in the liver parenchyme cells (van de Steeg et al., 2013). The transgenic promoter/enhancer used was chosen to obtain preferential expression of the human proteins in liver parenchyme cells, which was successful, although minor OATP1B1 and OATP1B3 transgene expression was also found in kidney, but not small intestine. Based on protein immunoblot analysis and protein mass spectrometry, the hepatic level of transgenic OATP1B1 was in the same order as that observed in human liver samples, and that of transgenic OATP1B3 somewhat higher, with estimated humanized/human ratios of 0.5 - to 1 -fold and $\sim 3$-fold for OATP1B1 and OATP1B3, respectively (Higgins et al., 2014; Salphati et al., 2014). Transgenic OATP1A2 expression was much higher than in human liver, but this relates mostly to the fact that OATP1A2 in human liver is only expressed in cholangiocytes, whereas in the transgenic mice it is expressed in the far more abundant liver parenchyme cells. This also means that the OATP1A2 humanized mouse strain does not represent a physiologically correct model of the normal OATP1A2 function in human liver. However, it does allow an assessment of the in vivo functioning of OATP1A2 in uptake of drugs and other compounds from plasma. This may, inter alia, be relevant as OATP1A2 is substantially expressed in the human blood-brain barrier, in apical membranes of kidney tubules, and in a variety of human tumors (van de Steeg et al., 2013 and references therein). Immunohistochemically, transgenic OATP1B1 was found in the sinusoidal membrane of hepatocytes and expressed throughout the liver lobule, albeit with stronger staining around the portal vein in human liver, whereas this transporter is variously reported to be expressed throughout the liver lobule, or primarily in centrilobular hepatocytes (van de Steeg et al., 2009, 2013). Transgenic OATP1B3 was likewise found in the hepatocyte sinusoidal membrane, showing somewhat dispersed distribution throughout the liver lobules 


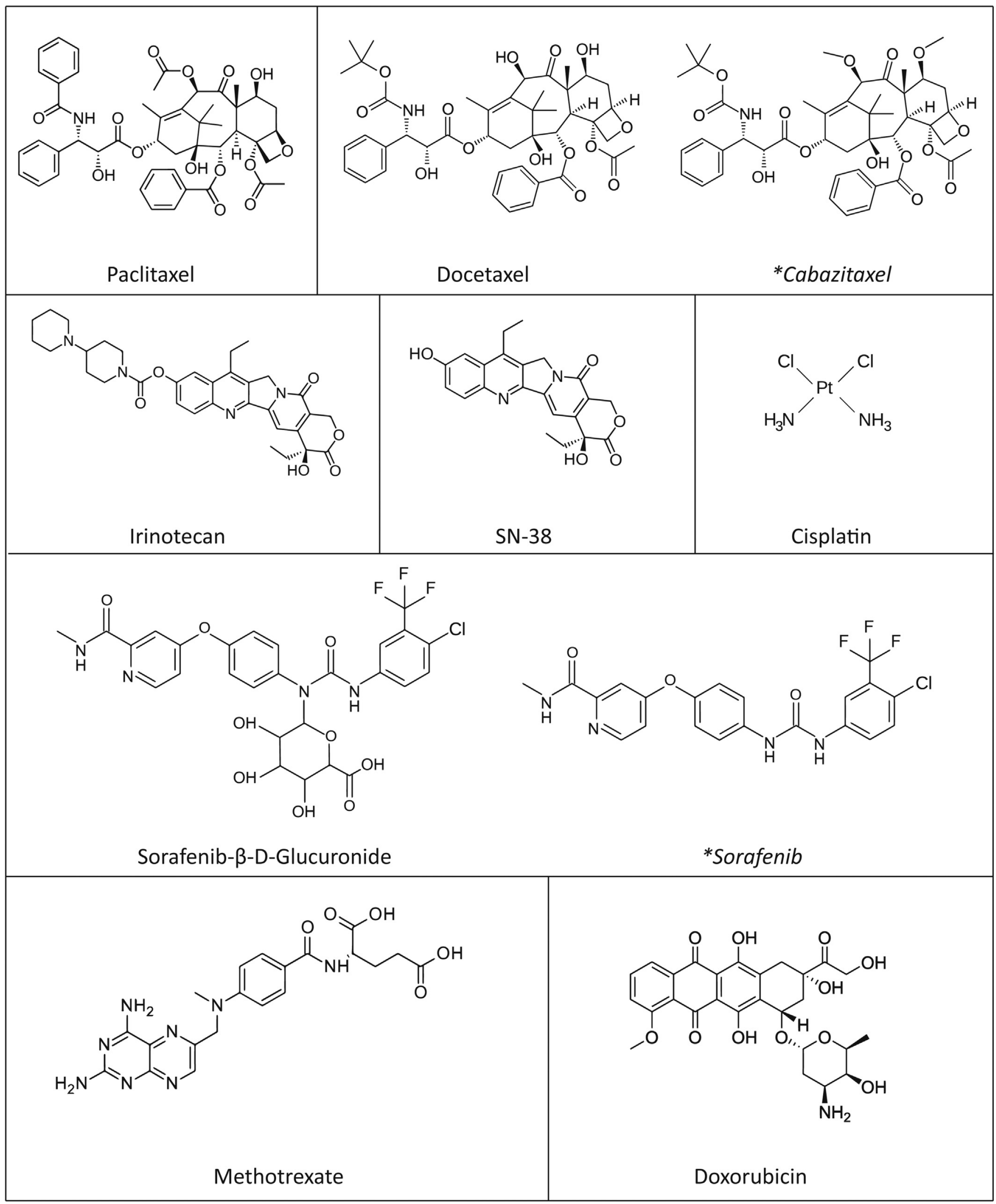

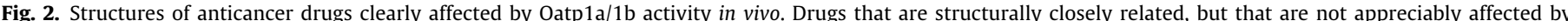

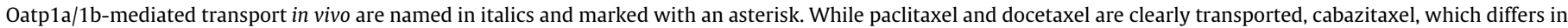

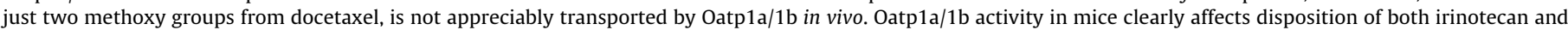

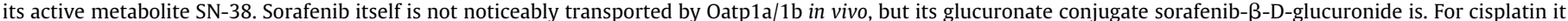

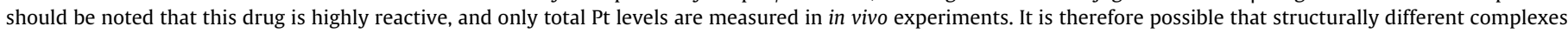
resulting from cisplatin reactions are primarily transported by Oatp1a/1b proteins. 
(van de Steeg et al., 2013). In human liver OATP1B3 is preferentially found in the sinusoidal membranes of centrilobular hepatocytes. Although the transgenic OATP1B1 and OATP1B3 therefore do not exactly reflect the lobular subdistribution of OATPs in human liver, subsequent studies revealed good functionality of these proteins (as well as transgenic OATP1A2) in the liver uptake and plasma clearance of a range of compounds.

Strong support for the functional activity of the hepatic OATP1B1, $-1 \mathrm{~B} 3$ and $-1 \mathrm{~A} 2$ transporters in the humanized strains came from the reversal of the highly increased plasma bilirubin levels found in the Oatp1a/1 $\mathrm{b}^{-1-}$ mice relative to wild-type mice (van de Steeg et al., 2013). The increased plasma levels of bilirubin monoglucuronide and diglucuronide were reversed to nearly wild-type levels ( $>15$-fold and $>7$-fold reduction, respectively) by both OATP1B1 and OATP1B3 expression, whereas OATP1A2 caused a more modest 2 -fold reduction. Interestingly, transgenic OATP1A2 was the only transporter that could significantly reduce the 2 -fold increased levels of unconjugated bilirubin back to wild-type levels. This suggests that OATP1A2 is a relatively more efficient transporter of unconjugated bilirubin compared to conjugated bilirubin, whereas the inverse is true for OATP1B1 and OATP1B3. What this means for the normal biological function of human OATP1A2 in cholangiocytes is as yet unclear. Perhaps it plays a role in the resorption of highly insoluble unconjugated bilirubin inadvertently formed in bile, thus reducing the chance of formation of bilirubincontaining gallstones, but for the moment this possibility remains speculative.

A limited pharmacokinetic study of paclitaxel in the OATP humanized mice revealed a modest, $\sim 1.6$-fold, but highly significant effect of OATP1B3 and OATP1A2 in enhancing the liver uptake of paclitaxel dosed i.v. at $2 \mathrm{mg} / \mathrm{kg}$ compared to that in Oatp1a/1b knockout mice. A smaller effect was observed at $10 \mathrm{mg} / \mathrm{kg}$ i.v. paclitaxel (only significant for OATP1A2). Transgenic OATP1B1 did not elicit significant changes relative to Oatp1a/1 $\mathrm{b}^{-/-}$mice at either dose (van de Steeg et al., 2013). Collectively, these data suggest that OATP1B3 and perhaps OATP1B1 may only have modest effects on paclitaxel liver uptake and clearance in humans. It should be kept in mind, though, that, unlike the situation in single humanized mice, in human liver OATP1B1 and OATP1B3 usually function simultaneously, which could well enhance their overall pharmacokinetic impact by additive effects. Such an additive effect was indeed observed for another drug in recently generated OATP1B1/1B3 double-transgenic mice, where single OATP1B1 or OATP1B3 transgenes did not markedly reduce the AUC of pravastatin after i.v. administration, but the combination reversed the AUC to close to that seen in wild-type mice (Salphati et al., 2014).

\subsubsection{Docetaxel}

Although quantitatively divergent results have been obtained for the impact of Oatp1b2 and Oatp1a/1b knockouts, and of various OATP1A2/1B1/1B3 humanized transgenes on docetaxel pharmacokinetics, all studies to date support a role of these OATP/Oatps in docetaxel clearance. De Graan et al. (2012) reported that after i.v. administration of docetaxel at $10 \mathrm{mg} / \mathrm{kg}$ to wildtype and Oatp1b2-l- mice, the plasma AUC was 26.3-fold higher in Oatp1b2 $2^{-1-}$ mice, indicating a very large effect of Oatp1b2 removal. As expected, the liver-to-plasma AUC ratio was reduced in Oatp1b2 $2^{-1-}$ mice, by 6.2-fold. However, somewhat surprisingly, the liver docetaxel AUC itself was substantially higher (4.3-fold) in Oatp1b2-I- compared to wild-type mice, rather than lower (or perhaps equal, see below). This result was unexpected in case the liver uptake of docetaxel was strongly reduced in the knockout mice. An analysis of potential compensatory expression changes of functionally related genes in the knockout mice did not yield obvious alternative causes of the changes in docetaxel pharmacokinetics. A simple mechanistic explanation of the observed increased liver AUC of docetaxel in the Oatp1b2- mice is for the moment therefore still lacking.

The potential experimental variability of these docetaxel pharmacokinetic studies was illustrated by the outcome of very similar experiments that were performed a few years later by the same group, in the same mouse strains, under apparently the same conditions (Hu et al., 2014; Sparreboom and Mathijssen, 2014). Instead of a 26-fold higher plasma AUC of docetaxel in the Oatp1b2-Imice, only a 1.6-fold increase was observed, which was, however, still statistically significant. The main difference was not a change over time in the plasma AUC of the Oatp1b2-l- mice ( 7400 vs. $\sim 8800 \mathrm{ng} x \mathrm{~h} / \mathrm{ml}$ ), but almost entirely attributable to a much higher plasma AUC of docetaxel in the wild-type mice compared to the earlier experiments (4500 vs. $336 \mathrm{ng} \mathrm{x} \mathrm{h} / \mathrm{ml}$ ). Despite extensive later analyses by the same group, the cause of these divergent results is still unclear (Sparreboom and Mathijssen, 2014). Although in our experience it is not uncommon to see some variation in absolute drug levels (AUC) measured in pharmacokinetic studies performed a few years apart under otherwise seemingly identical conditions, this usually concerns less than about 2-fold differences. However this may be, collectively, the data still indicate a role for Oatp1b2 in the clearance of i.v. docetaxel, most likely by mediating uptake of docetaxel from blood into the liver. This was further corroborated by independent studies by two other groups.

Using the same strain of Oatp1b2- $1-$ mice, Lee et al. (2015) very recently reported a limited, $30 \mathrm{~min}$ pharmacokinetic study with i.v. $\left[{ }^{3} \mathrm{H}\right]$-docetaxel dosed at $1 \mathrm{mg} / \mathrm{kg}$. By determining plasma and liver radioactivity, they found a 5.5-fold higher plasma AUC of $\left[{ }^{3} \mathrm{H}\right]-$ docetaxel equivalents in Oatp $1 \mathrm{~b} 2^{-1-}$ mice $(340 \pm 149$ vs $62 \pm 8 \mathrm{ng} \mathrm{x}$ $\mathrm{h} / \mathrm{ml}, P<0.05)$, no significant difference in liver concentrations, but a 3 -fold decreased liver-to-plasma ratio $(P<0.05)$. While concerning total radioactivity measurements, which may be complicated by extensive and possibly differential docetaxel metabolism, these results qualitatively support the findings of Hu et al. (2014) and De Graan et al. (2012), indicating a role of Oatp1b2 in plasma clearance of docetaxel by mediating uptake into the liver.

Iusuf et al. (2015) studied docetaxel pharmacokinetics in Oatp1a/1 $b^{-1-}$ mice of an FVB genetic background, using a lowpolysorbate 80 formulation to minimize possible inhibitory effects on Oatps (de Graan et al., 2012; Nieuweboer et al., 2014). After i.v. administration of docetaxel at $10 \mathrm{mg} / \mathrm{kg}$, the plasma AUC was 2.9-fold higher in the Oatp1a/1 $\mathrm{b}^{-1-}$ mice (609 vs $212 \mu \mathrm{g} \mathrm{x} \mathrm{min} / \mathrm{ml}$, $P<0.001$ ). Similar to the findings of Lee et al. (2015), the liver exposure was not substantially altered in the Oatp $1 \mathrm{a} / 1 \mathrm{~b}^{-/-}$mice, but the liver-to-plasma ratio was markedly lower at all except the earliest time points (at least 3-fold or more after $15 \mathrm{~min}$ ). A limited pharmacokinetic study (15-60 min) of i.v. docetaxel (dosed at $10 \mathrm{mg} / \mathrm{kg}$ ) in OATP1B1, OATP1B3, and OATP1A2 humanized mice indicated a 4-fold increase in docetaxel plasma AUC in Oatp1a/1 $\mathrm{b}^{-1-}$ compared to wild-type mice, which was largely reversed in both OATP1B1- and OATP1A2-transgenic mice $(P<0.001)$, and more modestly $(P<0.01)$ in OATP1B3-transgenic mice (Iusuf et al., 2015) (Fig. $3 \mathrm{~A}$ and $\mathrm{B}$ ). In accordance with the unaltered liver AUC in the Oatp1a/1 $b^{-1-}$ mice, the liver AUCs in all the humanized strains were not significantly different from those in the wild-type and Oatp $1 \mathrm{a} / 1 \mathrm{~b}^{-/-}$mice.

These unaltered liver AUC data are readily explained by a physiologically based pharmacokinetic model developed by Watanabe et al., 2009, 2010). This shows that a strong reduction in hepatic uptake of drugs that have little alternative extrahepatic clearance (e.g., renal clearance), will often result in markedly increased plasma levels of the drug, but only very small changes in the liver AUC. Accordingly, liver-to-plasma concentration ratios will decrease, but mainly due to the increased plasma concentrations of the drug. This is exactly the behavior that was observed for docetaxel in the studies of Iusuf et al. (2015) and Lee et al. (2015), but also 
A

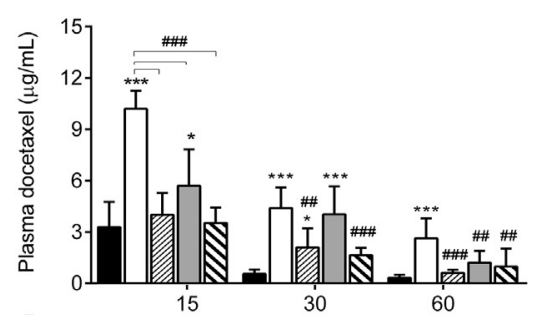

B

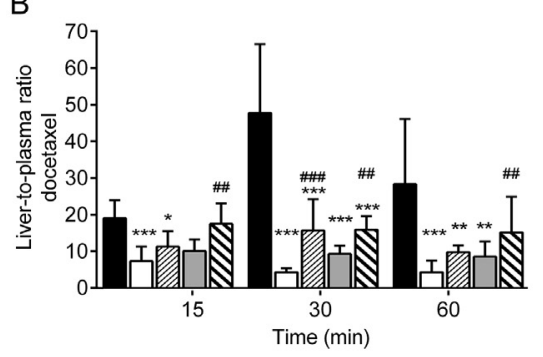

C

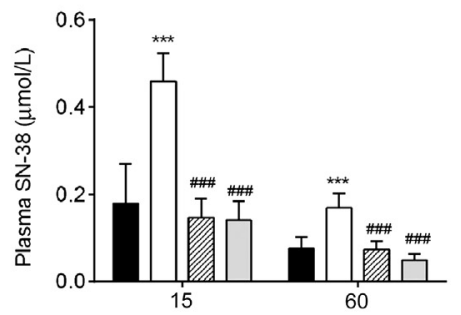

D

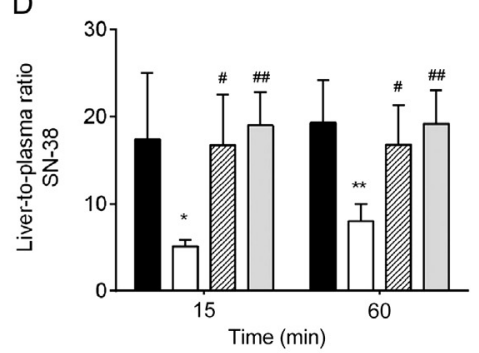

$\mathrm{E}$

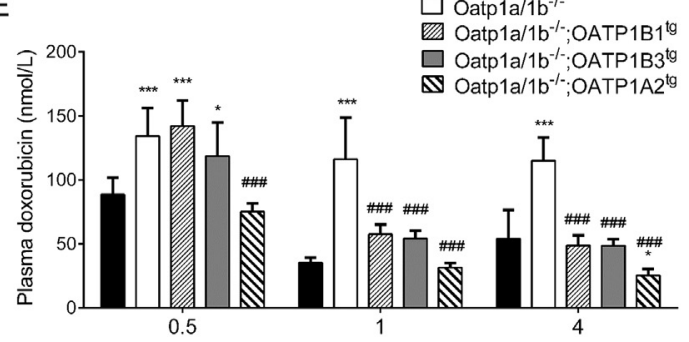

F

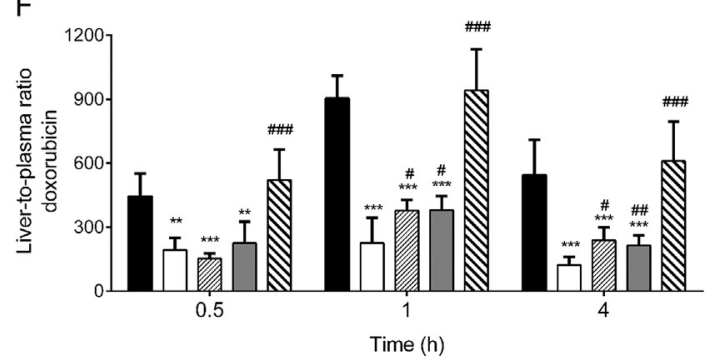

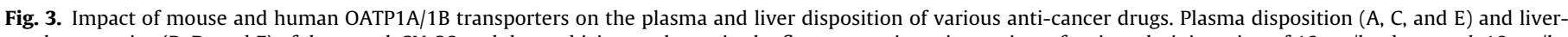

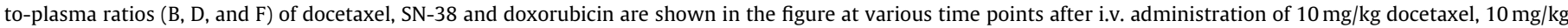

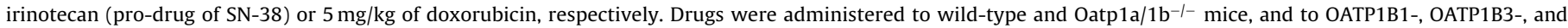

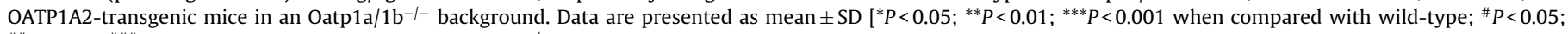

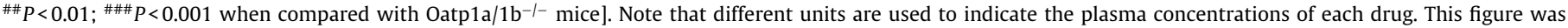
modified with permission from previously published experimental data of Iusuf et al. $(2015,2014)$ and Durmus et al. (2014).

earlier for rosuvastatin, another OATP substrate (Iusuf et al., 2013). Only the earlier data of De Graan et al. (2012), which appeared to show a $>4$-fold increase in liver AUC of docetaxel in Oatp1b2-Imice are not yet adequately explained.

Nonetheless, the collective data in Oatp knockout and various OATP1B-humanized strains provide strong support for the concept that mouse Oatp1b2 and human OATP1B1 and OATP1B3 in the sinusoidal membrane of the liver can contribute substantially to the liver uptake of docetaxel, and thus its plasma clearance as shown in Fig. 3A and B. It is further noteworthy that the contribution to docetaxel clearance of OATP1B1 and OATP1B3 in the human liver will likely be at least additive. It could therefore be that coadministration of docetaxel with strong inhibitors of OATP1B1 and OATP1B3 might result in unwarranted overexposure of patients to docetaxel, which only has a narrow therapeutic window.

\subsubsection{Cabazitaxel}

The taxane cabazitaxel was recently introduced in the clinic as a second-line treatment of hormone-refractory prostate cancer. Amongst others this compound is less affected by multidrug resistance caused by the MDR1 P-glycoprotein than docetaxel (Figg and Figg, 2010; Kathawala et al., 2015; Paller and Antonarakis, 2011) However, recent studies demonstrated that stepwise selection of MCF-7 cells to cabazitaxel resulted in P-gp overexpression (Duran et al., 2015). (Interestingly, cabazitaxel has a very similar structure as docetaxel, with the only difference being that two hydroxy groups in docetaxel are replaced by methoxy groups (Fig. 2). However, in spite of this great similarity to docetaxel, cabazitaxel appears not to be transported by human OATP1B1 and OATP1B3 or mouse Oatp1b2 in HEK293 cells, or in vivo in Oatp1b2 knockout mice (Nieuweboer et al., 2014). This illustrates how apparently minor structural modifications can sometimes have dramatic effects on whether a compound is transported by OATPs, as is also the case for MDR transporters of the ABC superfamily such as ABCG2 (Bram et al., 2009). On the positive side, this probably also means that for this drug, variations in OATP1B activity in patients due to genetic polymorphisms, drug-drug interactions or variable expression in tumors, are less likely to affect the therapeutic efficacy or toxicity.

\subsection{Irinotecan $/ \mathrm{SN}-38$}

The anticancer drug irinotecan is a topoisomerase I inhibitor widely used in the treatment of colorectal, ovarian and lung cancer. Its therapeutic index is quite low, in part owing to its complex pharmacokinetics involving a variety of metabolic enzymes and drug transporters. Irinotecan, essentially a prodrug, is hydrolyzed to its primary pharmacodynamically active metabolite, $\mathrm{SN}-38$, by various carboxylesterases occurring in liver, intestine, and, in mice, also in plasma (Innocenti et al., 2009; Mathijssen et al., 2002). Severe toxic side effects of irinotecan therapy include diarrhea and neutropenia, and these generally correlate with the systemic exposure to SN-38 (Smith et al., 2006). Low-activity polymorphic variants of OATP1B1, which may lead to impaired hepatic clearance of irinotecan and/or SN-38, are associated with increased systemic exposure to SN-38 and life-threatening toxicity (Han et al., 2008; Takane et al., 2009; Xiang et al., 2006). It was therefore of great interest to improve our understanding of the in vivo impact of OATPs on irinotecan/SN-38 pharmacokinetics and toxicity using a panel of Oatp/OATP knockout and transgenic mice. As it turned out, however, this study also revealed a potentially important confounder in studies with these mouse strains for drugs that can be affected by plasma carboxylesterases.

Initial studies of i.v. administered irinotecan $(10 \mathrm{mg} / \mathrm{kg})$ in wildtype and Oatp $1 \mathrm{a} / 1 \mathrm{~b}^{-1-}$ mice showed consistently higher plasma levels of irinotecan (AUC 1.7-fold higher) and SN-38 (AUC 2.9-fold higher) in the knockout mice, and roughly similar liver concentrations, resulting in clearly decreased liver-to-plasma ratios of both compounds in the knockouts at virtually all time points (Iusuf et al., 2014). This is consistent with reduced uptake of both these compounds from blood into the liver in the absence of Oatp1a/1b transporters, causing higher plasma levels. The amount of plasma SN-38 as a fraction of plasma irinotecan was $\sim 10 \%$ in wildtype mice, and $\sim 23 \%$ in knockout mice. A medium-term toxicity 
experiment, with daily i.v. administrations of irinotecan $(30 \mathrm{mg} / \mathrm{kg})$ over 6 days resulted in more extensive weight loss in the Oatp $1 \mathrm{a} / 1 \mathrm{~b}^{-1-}$ mice, and a more pronounced reduction in the white blood cell count than in the wild-type mice measured at the end of the experiment (day 7). Assessed at this same day 7, there was some toxicity to bone marrow, thymus, and small intestine in wild-type mice, but this was much more pronounced in Oatp $1 \mathrm{a} / 1 \mathrm{~b}^{-/-}$mice (Iusuf et al., 2014). These data were in line with a much higher plasma concentration of SN-38 in the Oatp $1 \mathrm{a} / 1 \mathrm{~b}^{-1-}$ mice measured $24 \mathrm{~h}$ after the last irinotecan administration, whereas the irinotecan concentrations at this time point were not significantly different from wild-type mice. It seems very likely that the higher exposure to $\mathrm{SN}-38$ in the Oatp $1 \mathrm{a} / 1 \mathrm{~b}^{-1-}$ mice was the main cause of the increased toxicity. The most obvious explanation for the higher SN38 exposure was strongly reduced hepatic clearance of SN-38, and likely also of its precursor irinotecan, by elimination of the mouse Oatp1a/1b transporters.

\subsubsection{Upregulation of plasma carboxylesterase in Oatp $1 a / 1 b^{-/-}$ mice}

Further analyses revealed, however, that the higher SN-38 exposure was not caused solely by a decreased clearance of $\mathrm{SN}-38$ directly due to a deficiency of Oatp1a/1b transporters. It turned out that, tested ex vivo, plasma of Oatp $1 \mathrm{a} / 1 \mathrm{~b}^{-/-}$mice contained a highly increased level of irinotecan hydrolase activity, which caused a far more rapid formation of SN-38 from irinotecan than observed in wild-type plasma. This difference was most likely the result of the highly increased expression of a number of carboxylesterase (Ces) genes in the liver of Oatp1a/1 $\mathrm{b}^{-1-}$ mice, namely Ces1b, Ces1c, Ces1d and Ces1e. Ces1c, which is relatively abundant, displayed an 80-fold increase in RNA levels (Iusuf et al., 2014). Interestingly, the mouse Ces1c enzyme is known to be mainly secreted from liver into plasma, due to the absence of a C-terminal endoplasmic reticulum retention signal in its amino acid sequence (Holmes et al., 2010). Application of the carboxylesterase inhibitor bis(4nitrophenyl) phosphate (BNPP) supported that increased plasma carboxylesterase activity was responsible for the hydrolysis of irinotecan in Oatp1a/1 $b^{-1-}$ plasma. Moreover, various other tested Ces1, Ces2, and Ces3 family genes, and genes for other candidate plasma esterase enzymes like butyrylcholinesterase, Aadac, and Pon $1-3$, were not upregulated in the Oatp $1 \mathrm{a} / 1 \mathrm{~b}^{-/-}$liver. Altogether, Ces1c upregulation is thus the most likely cause of the increased hydrolysis of irinotecan in Oatp $1 \mathrm{a} / 1 \mathrm{~b}^{-/-}$mice.

That the increase in Ces1c expression was a direct consequence of the functional Oatp1a/1b deficiency was strongly supported by analysis of Ces gene expression in OATP1B1- and OATP1B3humanized transgenic derivatives of Oatp $1 \mathrm{a} / 1 \mathrm{~b}^{-/-}$mice: the highly increased liver expression of Ces1c, but also of Ces1b, Ces1d and Ces1e, were markedly reduced, for Ces1c and Ces1d to even below the level of expression seen in wild-type mice, by both transgenic OATP1B1 and OATP1B3 (Iusuf et al., 2014). This indicates that the function of the removed Oatp1a/1b genes responsible for keeping liver Ces 1 expression low could be taken over by both human OATP1B1 and human OATP1B3. Still, the exact mechanism underlying these Ces-regulatory functions of Oatp/OATP1 proteins is as yet unclear. An obvious possibility appears to be a detoxifying function of these proteins, normally involved in removing one or more Ces-inducing compounds from the body. Such compounds might be of endogenous or exogenous origin (dietary, or metabolites or even primary products formed by the intestinal microflora), or possibly both. Their prolonged retention in the body might increase the overall liver exposure and thus Ces induction in the knockout strain. Further support for the involvement of a detoxifying role of the Oatp1a/1b proteins in Ces gene expression emerges from the finding that the knockout of a number of other broad-specificity detoxifying proteins in FVB mice, including the multidrug efflux transporters Abcb1a/1b and Abcg2, and the multidrug metabolizing Сур3a complex, cause similar levels of upregulation of hepatic Ces1b, Ces1c, Ces1d, and Ces1e expression (Lagas et al., 2012; Tang et al., 2015, 2014). Alternatively, a function of the OATPs in liver uptake of Ces-repressing compounds is also a possibility. If these compounds then get efficiently cleared through alternative routes, maybe renal or by metabolism, the effective liver exposure to these compounds might be reduced in the Oatp1a/1b knockout mice. However, for the moment these options remain speculative.

\subsubsection{Irinotecan studies in OATP1B1 and OATP1B3 humanized mice}

Whatever the mechanism of Ces upregulation, the increased plasma levels of Ces1c in Oatp1a/1 $\mathrm{b}^{-1-}$ mice might confound interpretation of the irinotecan and $\mathrm{SN}-38$ disposition and toxicity results in these mice. The increased conversion of irinotecan to $\mathrm{SN}-38$ could reduce plasma irinotecan levels, and increase SN38 levels independent of direct Oatp-mediated transport. For this reason, among others, i.v. irinotecan studies were also performed in the OATP1B1 and OATP1B3 humanized mice, as these have a mostly normalized plasma Ces1c activity. The results obtained for irinotecan and SN-38 were strikingly different: the humanized mice showed higher plasma levels of irinotecan compared to wildtype mice, but similar liver concentrations, resulting in markedly reduced liver-to-plasma ratios of irinotecan. As these differences cannot be attributed to Ces upregulation, the results suggest that the transgenic OATP1B1 and OATP1B3 are far less efficient (if at all) in taking up irinotecan into the liver than the mouse Oatp1a/1b proteins (which are absent from the humanized mice). This also explains the higher plasma levels of irinotecan in the humanized mice compared to wild-type mice.

In contrast, for SN-38 after i.v. irinotecan administration we found that the plasma levels in the transgenic mice were markedly reduced compared to Oatp $1 \mathrm{a} / 1 \mathrm{~b}^{-1-}$ mice, but similar to those in wild-type mice (Fig. 3C and D). In theory this could either be caused by the up- and down-regulation of Ces1c, or by changes in SN-38 clearance. Interestingly, the liver levels in all tested strains were the same, and the liver-to-plasma ratios of SN-38 were identical between the wild-type and transgenic strains, but markedly higher than in Oatp $1 \mathrm{a} / 1 \mathrm{~b}^{-1-}$ mice. The latter result strongly suggests that the liver uptake of SN-38 was compromised in the Oatp1a/1 $\mathrm{b}^{-/-}$ mice, and mostly restored by OATP1B1 and OATP1B3 in the humanized strains (Fig. 3 C and D).

\subsection{3. $\mathrm{SN}-38$ disposition in Oatp1a/1 $b^{-/-}$mice}

In an alternative approach to circumvent the complications of Ces upregulation in the Oatp $1 \mathrm{a} / 1 \mathrm{~b}^{-1-}$ mice, SN-38 was directly administered i.v. to these mice, at $1 \mathrm{mg} / \mathrm{kg}$ in view of the considerable solubility and formulation limitations of SN-38. This resulted in significantly higher plasma levels of SN-38 shortly after administration, and significantly lower liver concentrations compared to levels in wild-type mice. A reduced short-term liver uptake of SN38 was further supported by a two-fold decrease in biliary excretion of SN-38 in the Oatp1a/1 $\mathrm{b}^{-1-}$ mice (Iusuf et al., 2014).

Collectively, the mouse studies indicate that both irinotecan and SN-38 are cleared from plasma by uptake into the liver through one or more of the mouse hepatic Oatp1a/1b transporters. In contrast, the transgenic human OATP1B1 and OATP1B3 can mediate substantial liver uptake and plasma clearance of SN-38, but not of irinotecan. These results fit well with in vitro studies, which found that $\mathrm{SN}-38$ is readily transported by human OATP1B and OATP1B3, whereas irinotecan is not (Nozawa et al., 2005; Oostendorp et al., 2009; Yamaguchi et al., 2008). The results indicate species differences in substrate specificity between the mouse and human hepatic OATP1A/1B proteins, as expressed in vivo in mouse hepatocytes. The irinotecan/SN-38 toxicity data in the mouse strains are 
more difficult to interpret in view of the altered Ces1c levels and rate of $\mathrm{SN}-38$ formation in Oatp $1 \mathrm{a} / 1 \mathrm{~b}^{-1-}$ mice. However, extrapolating from the delayed hepatic SN-38 clearance in Oatp1a/1 $\mathrm{b}^{-/-}$ mice and its reversal by human OATP1B1 and OATP1B3, it seems very likely that also in humans these proteins are involved in the detoxification of SN-38. This would be in line with the clinical observations that partial deficiencies in OATP1B1 due to genetic polymorphisms correlate with increased irinotecan/SN-38 toxicity (Han et al., 2008; Takane et al., 2009; Xiang et al., 2006). The data of Iusuf et al. (2014) strongly suggest that this has primarily to do with delayed SN-38 clearance in these patients due to the compromised function of OATP1B1.

\subsection{Methotrexate}

Methotrexate is a folate antimetabolite that is used in the treatment of several important cancer types (breast cancer, lung cancer, head- and neck cancer, non-Hodgkin's lymphoma) (Assaraf, 2007; Gonen and Assaraf, 2012). It is also used, albeit at usually lower dosage, and mostly orally, to treat non-malignant disorders such as rheumatoid arthritis and psoriasis (van Outryve et al., 2002; Wessels et al., 2008). Methotrexate is a bicarboxylic organic anion, that is known to be transported in vitro by a number of OATP1A/1B proteins, including human OATP1B1, OATP1B3, and OATP1A2 (Abe et al., 2001; Badagnani et al., 2006; Sasaki et al., 2004). In addition, a genome-wide association study showed that SNPs in SLCO1B1 associated with reduced transport activity were linked to decreased plasma clearance and decreased gastrointestinal toxicity in children with acute lymphoblastic leukemia (ALL) treated with high-dose i.v. methotrexate infusions (Trevino et al., 2009).

\subsubsection{Methotrexate pharmacokinetics in Oatp1a/1b knockout mice}

Initial characterization of i.v. methotrexate pharmacokinetics in Oatp1a/1 $b^{-1-}$ mice revealed dramatic effects on plasma clearance and liver uptake of the drug (van de Steeg et al., 2010). The plasma AUC was increased 5-fold in Oatp $1 \mathrm{a} / 1 \mathrm{~b}^{-1-}$ mice, and liver concentrations were about 20-fold reduced. Hepatic methotrexate uptake was very rapid, with $>50 \%$ of the dose accumulating in the wild-type liver within $3.5 \mathrm{~min}$ after i.v. dosing, whereas only $\sim 2 \%$ of the drug accumulated in the liver of Oatp $1 \mathrm{a} / 1 \mathrm{~b}^{-1-}$ mice. As could be expected from the dramatically reduced liver uptake of methotrexate, the total intestinal content of i.v. methotrexate, which mostly derives from biliary excretion, was about 17 -fold reduced in the Oatp1a/1 $b^{-1-}$ mice. Accordingly, the amount of unchanged methotrexate excreted in the feces was reduced from $\sim 20 \%$ to $\sim 2 \%$ of the dose administered. In contrast, the urinary excretion rose from $\sim 40 \%$ of the dose in wild-type mice to $\sim 100 \%$ in Oatp $1 \mathrm{a} / 1 \mathrm{~b}^{-/-}$mice, indicating a substantial rerouting from hepatobiliary to renal excretion.

As some Oatp1a/1b proteins are also expressed in the mouse small intestine (Slco1a4, and to a lower extent Slco1a5 and Slco1a6 RNA were detected (Cheng et al., 2005), an oral methotrexate study was also performed to assess possible changes in oral availability. However, whereas the systemic plasma and liver concentrations of methotrexate followed similar patterns as seen after i.v. administration, short-term hepatic portal vein sampling didn't provide any indication for a reduced rate of intestinal uptake of methotrexate in the Oatp1a/1 $\mathrm{b}^{-/-}$mice. Apparently other intestinal uptake systems are primarily involved in the uptake of this bi-anionic compound.

In fact, despite extensive efforts, no one has thus far directly demonstrated for any OATP substrate drug that its intestinal uptake is detectably dependent on Oatp $1 \mathrm{a} / 1 \mathrm{~b}$ proteins. Directly tested drugs include, in addition to methotrexate, fexofenadine, pravastatin, and rosuvastatin (Iusuf et al., 2012a, 2013; van de Steeg et al.,
2010), as well as a number of other, as yet unpublished, drugs. This raises the broader question whether or not Oatp $1 \mathrm{a} / 1 \mathrm{~b}$ proteins play any significant role in the intestinal uptake of orally administered substrate drugs. However, there can be many causes for negative results in this respect, including the possibility of extensive redundancy with one or more other intestinal uptake transport systems. Further experimentation will be needed to resolve the intriguing question what transport systems are primarily involved in the intestinal uptake of a spectrum of relatively polar or charged drugs.

The Oatp $1 \mathrm{a} / 1 \mathrm{~b}^{-1-}$ mice can also be used to assess the efficacy and specificity of OATP-inhibiting drugs, for instance as a cause of drug-drug interactions. For this purpose rifampicin, a known OATP inhibitor, was administered i.v. 3 min before i.v. methotrexate to wild-type and Oatp $1 \mathrm{a} / 1 \mathrm{~b}^{-1-}$ mice, and methotrexate plasma and liver concentrations were determined 15 min later (van de Steeg et al., 2010). The methotrexate plasma concentration was increased threefold by rifampicin treatment in wild-type mice, to the same levels as seen in Oatp $1 \mathrm{a} / 1 \mathrm{~b}^{-1-}$ mice. In the knockout mice, rifampicin treatment had no effect on the plasma levels of methotrexate. The liver concentration of methotrexate in wild-type mice was 4 -fold decreased by rifampicin, to about $9 \%$ of the administered dose. The liver concentration in Oatp1a/1b knockout mice was still lower ( $\sim 1 \%$ of the dose), and not affected by rifampicin treatment. These results indicate that rifampicin could largely, but not completely, inhibit Oatp1a/1b-mediated methotrexate uptake into the liver, and thus its associated plasma clearance. The lack of effect of rifampicin on methotrexate pharmacokinetics in the Oatp $1 \mathrm{a} / 1 \mathrm{~b}^{-1-}$ mice indicates that it did not significantly affect other methotrexate clearance mechanisms, attesting to its specificity under these conditions.

\subsubsection{Methotrexate pharmacokinetics in OATP-humanized mice}

In a follow-up study, methotrexate pharmacokinetics was analyzed in OATP1B1-, OATP1B3- and OATP1A2-humanized Oatp1a/1 $\mathrm{b}^{-1-}$ mice (van de Steeg et al., 2013). As explained elsewhere in this review (Section 2.1.1), these three transgenes are primarily expressed in liver parenchyme cells in these mice, and the proteins are situated in the basolateral (sinusoidal) membrane. For OATP1B1 and OATP1B3 this is the physiologically relevant localization, but for OATP1A2 it is not, as in human liver it is found primarily in cholangiocytes, the epithelial cells lining the bile ducts. Still, inclusion of the latter strain allows analysis of the in vivo functioning of OATP1A2 in drug uptake, which can be relevant for assessment of any drug uptake that it may mediate in other tissues and in tumor cells.

Methotrexate was administered i.v. at two different doses (10 and $2 \mathrm{mg} / \mathrm{kg}$ ) to wild-type, Oatp $1 \mathrm{a} / 1 \mathrm{~b}^{-1-}$, and the three humanized mouse strains, and plasma, liver, and intestine (tissue plus contents) levels of methotrexate were measured $15 \mathrm{~min}$ after administration (van de Steeg et al., 2013). As observed previously, at $10 \mathrm{mg} / \mathrm{kg}$ in the knockout mice, methotrexate plasma levels were increased 5-fold, whereas liver levels were decreased 24-fold, and small intestine levels 20-fold (Table 2). Each of the three humanized transgenes partially reversed all of the three measured parameters, albeit not to the levels seen in wild-type mice. Plasma levels of methotrexate were reduced $\sim 2$-fold, and liver levels increased by 4 - to 9 -fold. Small intestinal levels were 2 - to 4 -fold increased. Qualitatively very similar results were obtained at the $2 \mathrm{mg} / \mathrm{kg}$ methotrexate dose (Table 2). In general, transgenic OATP1B3 and OATP1A2 caused a $\sim 2$-fold more effective reversal of liver and small intestinal concentrations than OATP1B1, whereas the plasma reversal effects were similar between the three transgenes. The partial reversal by the humanized OATP1B1 and OATP1B3 proteins compared to wild-type parameters could relate to species differences in substrate preference between mouse and human Oatp/OATP proteins, but also to differences in effective expression level. Also, 
Table 2

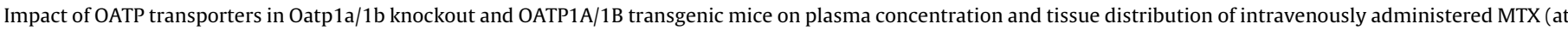
10 and $2 \mathrm{mg} / \mathrm{kg}, 15 \mathrm{~min}$ after administration).

\begin{tabular}{|c|c|c|c|c|}
\hline Dose & Mouse strains & Plasma concentration $(\mu \mathrm{g} / \mathrm{ml})$ & Liver amount (\% of dose) & Small intestine amount (\% of dose) \\
\hline \multirow{5}{*}{$10 \mathrm{mg} / \mathrm{kg}$} & WT & $1.55 \pm 0.24$ & $30.0 \pm 4.1$ & $20.9 \pm 1.4$ \\
\hline & Oatp1a/1 $\mathrm{b}^{-1-}$ & $7.59 \pm 0.76$ & $1.24 \pm 0.14$ & $0.94 \pm 0.17$ \\
\hline & Oatp1a/1b ${ }^{-/-} ; 1 \mathrm{~B} 1^{\mathrm{tg}}$ & $4.66 \pm 0.38$ & $4.54 \pm 1.24$ & $2.48 \pm 0.60$ \\
\hline & Oatp1a/1b ${ }^{-/-} ; 1 \mathrm{~B} 3^{\operatorname{tg}}$ & $4.35 \pm 0.52$ & $9.62 \pm 0.69$ & $5.21 \pm 1.03$ \\
\hline & Oatp $1 \mathrm{a} / 1 \mathrm{~b}^{-1-} ; 1 \mathrm{~A} 2^{\operatorname{tg}}$ & $4.03 \pm 1.00$ & $11.3 \pm 2.1$ & $5.81 \pm 2.56$ \\
\hline \multirow{5}{*}{$2 \mathrm{mg} / \mathrm{kg}$} & WT & $0.50 \pm 0.07$ & $33.0 \pm 5.1$ & $12.0 \pm 0.6$ \\
\hline & Oatp1a/1 $\mathrm{b}^{-1-}$ & $1.90 \pm 0.29$ & $1.65 \pm 0.14$ & $1.62 \pm 0.26$ \\
\hline & Oatp1a/1b ${ }^{-/-} ; 1 \mathrm{~B} 1^{\mathrm{tg}}$ & $0.93 \pm 0.18$ & $5.09 \pm 0.41$ & $2.56 \pm 0.60$ \\
\hline & Oatp1a/1b ${ }^{-1-} ; 1 \mathrm{~B} 3^{\operatorname{tg}}$ & $1.11 \pm 0.14$ & $10.2 \pm 1.2$ & $3.93 \pm 0.51$ \\
\hline & Oatp1a/1b ${ }^{-1-} ; 1 \mathrm{~A} 2^{\operatorname{tg}}$ & $0.88 \pm 0.11$ & $9.07 \pm 0.96$ & $3.76 \pm 0.51$ \\
\hline
\end{tabular}

in human liver OATP1B1 and OATP1B3 would presumably act additively towards methotrexate, and thus may cause larger pharmacokinetic effects than suggested by the effects seen in the single transgenic strains. Regardless, the data clearly show that human OATP1B1 and OATP1B3 can have major effects on the plasma level, hepatic uptake clearance, and subsequent hepatobiliary/intestinal excretion of methotrexate. Moreover, as OATP1B3 is also expressed in various gastrointestinal, hepatocellular, breast, and lung cancers, it may further affect susceptibility of these cancers to OATP1B3 substrate drugs (Abe et al., 2001; Cui et al., 2003; Monks et al., 2007; Muto et al., 2007). The data obtained for human OATP1A2 suggest that this protein could substantially affect methotrexate uptake in vivo in other relevant tissues and barriers, such as the blood-brain barrier, kidney tubules, and tumor cells that express OATP1A2 (Gao et al., 2000; Lee et al., 2005).

\subsubsection{Impact of rifampicin and telmisartan co-administration on OATP-mediated methotrexate disposition}

The humanized mouse strains were subsequently used to further investigate OATP-dependent drug-drug interactions, starting with the inhibitory effect of rifampicin on in vivo methotrexate transport by human OATP1B1 and OATP1B3. Using various human OATP-overexpressing HEK293 cells, Durmus et al. (2015) showed that rifampicin inhibited methotrexate uptake in vitro, with $\mathrm{IC}_{50}$ levels ranging from 0.3 to $0.9 \mu \mathrm{M}$. In the mouse models, rifampicin $(20 \mathrm{mg} / \mathrm{kg}$, i.v.) substantially inhibited both mouse and human OATP-mediated hepatic uptake and plasma disposition of methotrexate $(10 \mathrm{mg} / \mathrm{kg}$, i.v.) at clinically achievable concentrations for each of the drugs. As shown in Table 3, liver-to-plasma ratios of methotrexate were decreased 6- to 8-fold by inhibiting the mouse Oatp1a/1b proteins, $\sim 4$-fold by inhibiting human OATP1B1 and 11 - to 18 -fold by inhibiting human OATP1B3. This also led to increased plasma levels of methotrexate by 4 - to 5 -fold in mouse Oatp1a/1b background and up to 2-fold in humanized OATP1B1 or OATP1B3 background (Table 3).

Although this specific combination of drugs (methotrexate and rifampicin) would be rare in the clinic, these results still suggest that more than one OATP-substrate or -inhibitor drugs might bring the risk of drug-drug interactions at the systemic and hepatic level. This would be especially important for patients chronically taking OATP-interacting drugs, such as statins and hypertension drugs. More importantly, people who already have activity-reducing polymorphisms in their OATP genes (Nakanishi and Tamai, 2012) might be at increased risk for altered drug disposition due to this type of drug-drug interactions, and consequently ineffective treatment and/or increased toxicity.

The possible drug-drug interaction effect of a clinically more common drug combination was investigated using a hypertensive drug, telmisartan, and methotrexate. This also allowed further evaluation of the applicability of knock-out and humanized mouse strains in drug-drug interaction studies. A similar set-up to the rifampicin and methotrexate experiments was chosen, but the dose of telmisartan had to be kept lower $(7 \mathrm{mg} / \mathrm{kg})$ due to solubility issues. In vitro cellular uptake studies resulted in fairly but not very low $\mathrm{IC}_{50}$ levels for telmisartan inhibiting methotrexate uptake $(<11 \mu \mathrm{M})$, and in vivo studies in the mouse models showed that telmisartan pre-treatment did not yield important changes in methotrexate disposition. There was only a weak inhibition of OATP1B1-mediated hepatic uptake of methotrexate by telmisartan, leading to $\sim 2$-fold decreased liver-to-plasma ratios of methotrexate. However, comparing the systemic telmisartan levels (40-200 nM) in patients (Stangier et al., 2000) with the levels achieved in mouse plasma $(7-13 \mu \mathrm{M})$ suggests only a very low risk of adverse OATP-mediated drug-drug interactions between telmisartan and methotrexate in the clinic. These findings are helpful for patients who are simultaneously treated with methotrexate and telmisartan. However, additional clinically relevant combinations of drugs that are OATP-substrates and/or -inhibitors should be tested to evaluate the risks of OATP-mediated drug-drug interactions in the clinic, especially for the systemic and hepatic effects on drug concentrations due to the function of OATPs in liver uptake of their substrates. We suggest that the humanized transgenic mouse models with liver-specific OATP expression could be used to obtain a more realistic view of the human situation. However, it should be noted that these mouse models, while very useful to support the development of basic mechanistic insights, should not be used as simple one-to-one models of drug behavior in humans.

\subsection{Doxorubicin}

Doxorubicin, an important topoisomerase II inhibitor drug used in cancer treatment, was recently shown to be an OATP substrate (Durmus et al., 2014). Doxorubicin is an anthracycline antibiotic, commonly used in the treatment of several cancers, including Hodgkin's and non-Hodgkin's lymphoma, multiple myeloma, leukemia, sarcoma and breast, ovarian, thyroid, gastric and lung cancers (Cortes-Funes and Coronado, 2007; Gewirtz, 1999). Various modes of action have been described for doxorubicin, of which two major mechanisms are intercalation of DNA that leads to inhibition of the topoisomerase II enzyme, required for smooth DNA transcription and replication, and, perhaps more controversially, generation of free radicals that leads to DNA and cell membrane damage (Gewirtz, 1999). Cardiotoxicity is the major and doselimiting side effect of doxorubicin both in adult and pediatric cancer patients (Grenier and Lipshultz, 1998). Thus, recent efforts to improve doxorubicin treatment focus on improved anti-tumor efficacy and decreased cardiotoxicity by developing tumor-targeting strategies such as liposomal formulations of doxorubicin or developing new doxorubicin analogs (Cortes-Funes and Coronado, 2007; Minotti et al., 2004). Another strategy for lowering the toxicity and increasing the efficacy of doxorubicin is to understand the factors affecting its tissue disposition, such as its interactions with drug 
Table 3

Impact of rifampicin pre-treatment on the plasma levels and liver-to-plasma ratios of methotrexate in WT, Oatp knockout and OATP1B humanized transgenic strains.

\begin{tabular}{|c|c|c|c|c|c|c|}
\hline \multirow[b]{2}{*}{ Time point } & \multirow[b]{2}{*}{ Parameter } & \multirow[b]{2}{*}{ Rifampicin } & \multicolumn{4}{|c|}{ Mouse strains } \\
\hline & & & WT & Oatp1a/1b $\mathrm{b}^{-1-}$ & Oatp1a/1b ${ }^{-/-} ; 1 \mathrm{~B} 1^{\mathrm{tg}}$ & Oatp1a/1b-l- $; 1 \mathrm{~B} 3^{\text {tg }}$ \\
\hline \multirow{6}{*}{$5 \mathrm{~min}$} & \multirow[t]{2}{*}{ Plasma concentration (nmol/ml) } & - & $11.9 \pm 1.7$ & $46.6 \pm 7.4$ & $49.0 \pm 15.3$ & $32.2 \pm 3.7$ \\
\hline & & + & $50.2 \pm 7.8$ & $67.7 \pm 3.5$ & $53.6 \pm 9.4$ & $62.3 \pm 6.9$ \\
\hline & \multirow{3}{*}{$\begin{array}{l}\text { Rifampicin-induced fold increase } \\
\text { Liver-to-plasma ratio }\end{array}$} & & 4.2 & 1.5 & 1.1 & 1.9 \\
\hline & & - & $15.5 \pm 2.0$ & $0.2 \pm 0.0$ & $0.5 \pm 0.1$ & $1.7 \pm 0.3$ \\
\hline & & + & $1.9 \pm 0.3$ & $0.1 \pm 0.0$ & $0.2 \pm 0.0$ & $0.2 \pm 0.0$ \\
\hline & Rifampicin-induced fold decrease & & 8.2 & 2.0 & 2.5 & 8.5 \\
\hline \multirow{6}{*}{$15 \mathrm{~min}$} & \multirow[t]{2}{*}{ Plasma concentration $(\mathrm{nmol} / \mathrm{ml})$} & - & $6.6 \pm 2.7$ & $31.2 \pm 13.4$ & $43.1 \pm 4.2$ & $19.5 \pm 10.3$ \\
\hline & & + & $30.7 \pm 12.9$ & $43.9 \pm 14.1$ & $46.4 \pm 10.0$ & $43.1 \pm 18.8$ \\
\hline & Rifampicin-induced fold increase & & 4.7 & 1.4 & 1.1 & 2.2 \\
\hline & \multirow[t]{2}{*}{ Liver-to-plasma ratio } & - & $27.0 \pm 5.9$ & $0.2 \pm 0.0$ & $1.1 \pm 0.2$ & $5.1 \pm 1.4$ \\
\hline & & + & $4.7 \pm 2.5$ & $0.2 \pm 0.0$ & $0.3 \pm 0.1$ & $0.3 \pm 0.0$ \\
\hline & Rifampicin-induced fold decrease & & 5.7 & 1.0 & 3.7 & 17.0 \\
\hline
\end{tabular}

transporters, and utilize these insights to modify the pharmacokinetics, possibly with transporter inhibitors. Although doxorubicin has been used in the clinic for a very long time, information on its interaction with drug uptake transporters has been very limited. Okabe et al. (2005) suggested for the first time that doxorubicin might enter cells via organic cation transporter (OCT6)-mediated active transport.

Very recently, it was shown that both mouse and human OATP1A/1B family members can mediate cellular uptake of doxorubicin (Durmus et al., 2014). This was rather surprising, as its structure, with properties of a weak base, was not considered a typical OATP substrate. In human OATP1A2-overexpressing HEK293 cells, the uptake of doxorubicin was $\sim 2$-fold increased compared to control cells, but there was no noticeable transport by human OATP1B1 or OATP1B3 in vitro. Mouse Oatp1a/1b proteins transported doxorubicin in vivo, as evidenced by up to $\sim 2$-fold increased plasma concentrations and up to 4 -fold decreased liver-to-plasma ratios in Oatp $1 \mathrm{a} / 1 \mathrm{~b}^{-1-}$ mice after i.v. doxorubicin administration (Fig. 3E and F) (Durmus et al., 2014). Moreover, the doxorubicin levels in the small intestinal content were also reduced in the knockout mice, suggesting a decreased biliary output, probably due to the lower liver levels. Interestingly, addition of one of the human OATP1A or 1B transporters in transgenic mice (on a mouse Oatp1a/1b knockout background) rescued the altered levels seen in the knockout mice to various extents (Fig. 3E and F). Transgenic liver-specific expression of human OATP1A2 could completely reverse the hepatic uptake and intestinal excretion of doxorubicin back to wild-type levels, whereas that of human OATP1B1 or OATP1B3 resulted in partial, but substantial rescue of these phenotypes (Durmus et al., 2014). Only the OATP1B1 or OATP1B3 transporters alone were present in these transgenic mouse livers, instead of both simultaneously as in humans. The substantial impact of either transporter alone therefore suggests an even stronger impact of OATP1Bs on doxorubicin pharmacokinetics in humans, especially affecting plasma clearance and hepatic uptake characteristics. Obviously, for a drug with a narrow therapeutic index like doxorubicin, this might be critical for its therapeutic efficacy and toxicity in patients. It may therefore also be of interest to investigate possible associations between OATP transport activity and doxorubicin pharmacokinetics, therapeutic efficacy, and toxicity in patient cohorts.

\subsection{Platinum chemotherapeutics}

Cisplatin and more recent platinum chemotherapeutics such as carboplatin and oxaliplatin are used to treat a wide spectrum of cancers, including testicular, bladder, lung, ovarian, colorectal, cervical, and breast cancers, as well as some lymphomas and sarcomas. In a COMPARE analysis of 60 human tumor cell lines (the well-characterized NCI-60 panel), Lancaster et al. (2013) found that high OATP1B3 expression, as judged by Real-time RT-PCR, was significantly linked with sensitivity to the cytotoxicity of 9 anticancer drugs, amongst which cisplatin, carboplatin, and a platinum compound structurally related to oxaliplatin. Unlike OATP1B1, which was found to be only expressed in liver and liver tumor tissue, OATP1B3 was found expressed in a range of different tissues and derived tumor tissue samples, suggesting that it might play a role in tumor sensitivity to platinum compounds.

Subsequent in vitro studies revealed that human OATP1B3 and OATP1B1 can mediate the cellular uptake of Pt upon exposure to cisplatin, and additionally OATP1B3 can mediate cellular Pt uptake upon exposure to carboplatin and oxaliplatin. In vivo studies with cisplatin administered intraperitoneally to wild-type and Oatp1b2-I- mice showed up to 35\% reduced liver levels of Pt in the knockout mice shortly after administration, and 2.5-fold higher urinary excretion of Pt, the latter amounting to more than $60 \%$ of the administered dose (Lancaster et al., 2013). The data suggest a rapid and substantial liver uptake of a fraction of Pt being mediated by Oatp1b2 in wild-type mice. In the Oatp1b2-1- mice, this Pt fraction may instead be excreted primarily into the urine. As a consequence, the plasma levels of Pt are not much different between the two strains. It should be noted, however, that cisplatin is highly reactive, for instance with carbonate, and the Oatp1b2-mediated Pt uptake may therefore well represent uptake of various resulting negatively charged Pt complexes instead of cisplatin itself. Cisplatin also binds irreversibly to plasma proteins, further complicating pharmacokinetic analyses. However that may be, in vivo Oatp1b2 function does clearly affect the pharmacokinetics of cisplatin-derived Pt. Extrapolating to human patients, this could mean that variations in OATP1B1 and OATP1B3 expression and transport activity in liver, in other tissues, and especially in tumors, might affect the efficacy and toxic side effects of cisplatin-based chemotherapy. It will therefore be of interest to extend preclinical studies of cisplatin to OATP1B1and OATP1B3-humanized Oatp1a/1b knockout strains, and also include studies of carboplatin and oxaliplatin. It will further be worthwhile to assess whether part of the high inter-individual variation in efficacy and toxicity of these drugs seen in patients can in part be attributed to variations in OATP function.

\subsection{Tyrosine kinase inhibitors}

Tyrosine kinase inhibitors (TKIs), with the prime example imatinib (Gleevec), have revolutionized the treatment of a number of malignancies (Druker et al., 2001). As of 2015, more than 28 TKIs have been FDA-approved (Wu et al., 2015). These rationally designed, targeted anticancer drugs can make use of specific vulnerabilities of tumor cells, for instance by targeting specific oncogenic mutations in protein tyrosine kinases, thus increasing 
disease-specificity and reducing the risk of toxic side effects. Understandably, there has been significant interest in whether TKIs are OATP transport substrates, as this could affect their accumulation in tumor cells as well as in various important tissues, and control their plasma pharmacokinetics and elimination. Such parameters can be decisive in the overall therapeutic efficacy and tolerability of anticancer and other therapeutic agents.

While many TKIs have now been tested for interaction with OATPs, the in vivo relevance for transport of the unconjugated parent compounds appears to be limited. In RNA-injected Xenopus oocytes, human OATP1A2 mediates modest imatinib uptake, OATP1B3 a little, and OATP1B1 none (Hu et al., 2008). Initial tests failed to show significant uptake of sorafenib and sunitinib mediated by OATP1A2, OATP1B1, and OATP1B3 in RNA-injected Xenopus laevis oocytes (Hu et al., 2008). However, later studies with highly OATP-overexpressing HEK293 cells reported significant uptake of crizotinib, nilotinib, pazopanib, and sorafenib by OATP1B1 and OATP1B3 of imatinib, gefitinib, dasatinib, vandetanib, and vemurafenib by OATP1B3 but not by OATP1B1; and of sunitinib by OATP1B1 but not by OATP1B3 (Zimmerman et al., 2013). It should be noted, however, that often relative levels of uptake of TKIs mediated by OATP in the various in vitro model systems were small compared to those of the anionic OATP control substrates. Modern targeted TKIs are rarely, if at all, designed to be anionic, given the usual requirements of good oral availability (intestinal absorption) and efficient tumor cell penetration of these compounds. A possible further cause of discrepancies between in vitro and in vivo OATP-mediated transport results for certain drugs is discussed later in Section 4 of this review.

\subsubsection{In vitro and in vivo studies with sorafenib}

The TKI sorafenib was further investigated in vivo in mouse models because it was readily transported by both OATP1B1 and OATP1B3 in vitro. Unlike its conjugate, sorafenib-glucuronide, which will be discussed later, the plasma pharmacokinetics of parent sorafenib, or its relative accumulation in the liver, was not substantially altered in either Oatp1b2-/- mice (DBA background strain), or in Oatp1a/1 $b^{-1-}$ mice (FVB background strain) after administration of $10 \mathrm{mg} / \mathrm{kg}$ oral sorafenib (Zimmerman et al., 2013). A partial explanation might be that in vitro sorafenib was poorly transported by mouse Oatp1b2. However, sorafenib transport by the two other prominent sinusoidal uptake transporters in the mouse liver, Oatp1a1 and Oatp1a4, was not tested in vitro, so it remains uncertain whether or not there is an in vitro/in vivo discrepancy (Zimmerman et al., 2013).

Some TKIs have been further evaluated for their ability to inhibit human OATP1B1 in vitro and in vivo (Hu et al., 2014). These studies were triggered by clinical observations that co-administration of several TKIs can increase the systemic exposure to docetaxel in cancer patients. The underlying mechanism was poorly understood, but, as docetaxel clearance may in part depend on OATP function (see Section 2.1.2), it might involve inhibition of OATPs by these TKIs (Hu et al., 2014). Nearly all 16 tested TKIs inhibited E2G uptake by human OATP1B1 in vitro when applied at $10 \mu \mathrm{M}$, and 4 of these TKIs (axitinib, nilotinib, pazopanib, and sorafenib) by more than 10-fold. Interestingly, three of these (axitinib, pazopanib, and sorafenib) are known to increase the docetaxel AUC by up to $50 \%$ or more when co-administered in patients (clinical data for nilotinib/docetaxel co-administration are not available). Further analysis of sorafenib showed that it inhibited docetaxel uptake by OATP1B1 in vitro with an $\mathrm{IC}_{50}$ below $100 \mathrm{nM}$, and very extensively when applied at $10 \mu \mathrm{M}$. Mouse Oatp1b2 showed similar inhibition of E2G and docetaxel transport by sorafenib in vitro. In vivo, however, no significant effect of high-dose $(60 \mathrm{mg} / \mathrm{kg})$ oral sorafenib co-administration could be demonstrated on $10 \mathrm{mg} / \mathrm{kg}$ i.v. docetaxel plasma $C_{\max }$ or AUC in wild-type, Oatp1b2- $2^{-1-}$, Oatp1a/1 $1 \mathrm{~b}^{-1-}$, or in OATP1B1-humanized mice. Moreover, multiple sorafenib administrations did not elicit significant effects (Hu et al., 2014). Of note, in these specific experiments (see also Section 2.1.2), the effects of Oatp1b2 knockout or OATP1B1 transgenics on docetaxel AUC were relatively modest (about 2 -fold). This may have rendered these experiments less sensitive to picking up small pharmacokinetic effects of sorafenib-mediated inhibition. The absence of an obvious pharmacokinetic interaction between sorafenib and docetaxel in the various mouse strains suggests that there may be other factors in mice, perhaps alternative or compensatory mechanisms that can sufficiently offset any changes in OATP1B-like activity towards docetaxel clearance. Here too, one has to consider the possibility that interactions of OATPs with certain drugs may depend on the cellular context in which they are expressed (in this case mouse hepatocytes). However that may be, at the present time it remains uncertain whether or not the observed clinical pharmacokinetic interaction between sorafenib and docetaxel is mediated through OATP1B1, or rather by some other mechanism(s).

\section{Hepatocyte hopping of a conjugated anticancer drug: The case of sorafenib glucuronide}

In contrast to the nearly absent effect of Oatp1b2 or Oatp $1 \mathrm{a} / 1 \mathrm{~b}$ deficiency on the pharmacokinetics of orally administered sorafenib, in the same experiments a pronounced increase in plasma levels of sorafenib glucuronide was observed, with a 5.5-fold increased AUC in Oatp1b2-1- mice, and 29-fold in Oatp $1 \mathrm{a} / 1 \mathrm{~b}^{-1-}$ mice; although the bigger relative increase in the latter case mainly arose from a substantially lower AUC of sorafenib glucuronide in wild-type FVB mice than in wild-type DBA mice, with the plasma AUCs in both the knockout strains being similar (Zimmerman et al., 2013). The plasma levels of sorafenib glucuronide in the knockout strains equaled or surpassed those of parental sorafenib itself, indicating the quantitative importance of this process. Subsequent in vitro experiments indicated that sorafenib glucuronide was efficiently taken up by mouse Oatp1b2 and human OATP1B1 and OATP1B3 expressed in HEK293 cells. Furthermore, transgenic expression of either human OATP1B1 or OATP1B3 in the liver of "humanized" Oatp1a/1 $\mathrm{b}^{-1-}$ mice resulted in a partial reversal of the increased plasma sorafenib glucuronide levels (Zimmerman et al., 2013). This confirmed a prominent role of the mouse and human sinusoidal OATP transporters in hepatic uptake of sorafenib glucuronide.

An important question was the origin of the sorafenib glucuronide, as it is known that both enterocytes and hepatocytes can have substantial drug glucuronidation capacity, and oral sorafenib might undergo rapid glucuronidation in the intestinal wall upon absorption. However, mouse intestinal microsomes showed only marginal sorafenib glucuronidation capacity, compared to mouse liver microsomes ( $>50$-fold difference), suggesting that most sorafenib glucuronide had been formed in the liver (Zimmerman et al., 2013). Taken together, these findings suggested strongly that under normal conditions a substantial part of sorafenib glucuronide formed in the liver is extruded across the sinusoidal membrane into the blood, and then taken up again into the liver by Oatp1b2, OATP1B1, and OATP1B3.

\subsection{Hepatocyte hopping of bilirubin glucuronide}

This process inferred to explain the behavior of sorafenib glucuronide was highly reminiscent of the previously proposed "hepatocyte hopping" process for the endogenous metabolite bilirubin glucuronide (Iusuf et al., 2012c; van de Steeg et al., 2012, 2010). The hydrophobic, very poorly water-soluble, and potentially highly toxic unconjugated bilirubin, the primary breakdown 
product of heme (from hemoglobin) degradation, is directly transported from the spleen, where red blood cells are mostly degraded, via the splenic and portal veins, to the liver. Extensive binding to plasma albumin prevents precipitation of bilirubin in blood. Bilirubin is then efficiently taken up into the liver, presumably in part by Oatp1a/1b transporters, but also by one or more other, substantial, transport mechanisms, which may or may not include passive diffusion. Inside the hepatocytes bilirubin is efficiently conjugated by UGT1A1 to yield bilirubin glucuronide, which is more water-soluble and generally easier to detoxify by the body. Normally, the bulk of hepatic bilirubin glucuronide is excreted into the bile by the ABCC2 multidrug efflux transporter and then released into the small intestine lumen to leave the body through the feces. However, analysis with a range of different single and combination transporter knockout and transgenic mouse strains has revealed that also under physiological conditions, a substantial fraction of hepatic bilirubin glucuronide (possibly up to half of the total amount formed) is secreted by the multidrug efflux transporter $A B C C 3$ across the basolateral (sinusoidal) membrane of hepatocytes into the blood (van de Steeg et al., 2013, 2010). Most of this bilirubin glucuronide is quickly taken up again into the liver by Oatp1a/1b proteins in the mouse, and by OATP1B1 and OATP1B3 in humans, a cycle resulting in very low overall plasma levels of conjugated bilirubin in the general circulation. In contrast, in mice that lack Oatp1a/1b proteins, or in humans that lack both OATP1B1 and OATP1B3 in the liver, the interruption of this cycle leads to highly increased plasma levels of conjugated bilirubin in the circulation, and somewhat increased levels of unconjugated bilirubin, causing a disorder known as Rotor syndrome (van de Steeg et al., 2012). The phenotype of this Rotortype conjugated hyperbilirubinemia is fortunately quite benign, mainly a generally mild jaundice.

The underlying mechanistic process, where bilirubin glucuronide is secreted from a hepatocyte by ABCC 3 into the sinusoidal blood, only to be taken up again in a downstream hepatocyte via Oatp1a/1b or OATP1B proteins, has been called "hepatocyte hopping", as it allows bilirubin glucuronide to readily "hop" from one hepatocyte to the next. It has been speculated that this hepatocyte hopping process might be beneficial under circumstances where the bile canalicular excretion of bilirubin glucuronide through ABCC2 in upstream situated hepatocytes is overloaded or otherwise compromised. The hepatocyte hopping salvage pathway for such trapped bilirubin glucuronide allows it to be secreted back into the blood, and taken up into a downstream hepatocyte, where it has another chance of being excreted into the bile, and so on, and so forth. This added flexibility in the hepatobiliary excretion process of bilirubin glucuronide might reduce the risk of toxic damage due to glucuronide accumulation in upstream hepatocytes (Iusuf et al., 2012b,c; van de Steeg et al., 2012, 2010).

\subsection{Hepatocyte hopping of sorafenib glucuronide}

It has been theorized that this same hepatocyte hopping process might apply to many drugs that are extensively glucuronidated in the liver as well, as the transporters involved $(A B C C 2, A B C C 3$, OATP1B1 and OATP1B3 in human, Abcc2, Abcc3 and Oatp1a/1b proteins in mouse) are all known to have very broad substrate specificities, that include the glucuronide conjugates of many compounds (Iusuf et al., 2012c; van de Steeg et al., 2010). Especially as the glucuronide conjugates of several drugs are thought to be important in yielding reactive intermediates that could cause direct or indirect liver damage and toxicity (Zhou et al., 2005), it would be very important to have a mechanism that can relieve the intracellular exposure level of the hepatocyte to these glucuronide conjugates also when canalicular excretion is compromised.

The findings with sorafenib glucuronide described above suggested that sorafenib might present an example of a drug

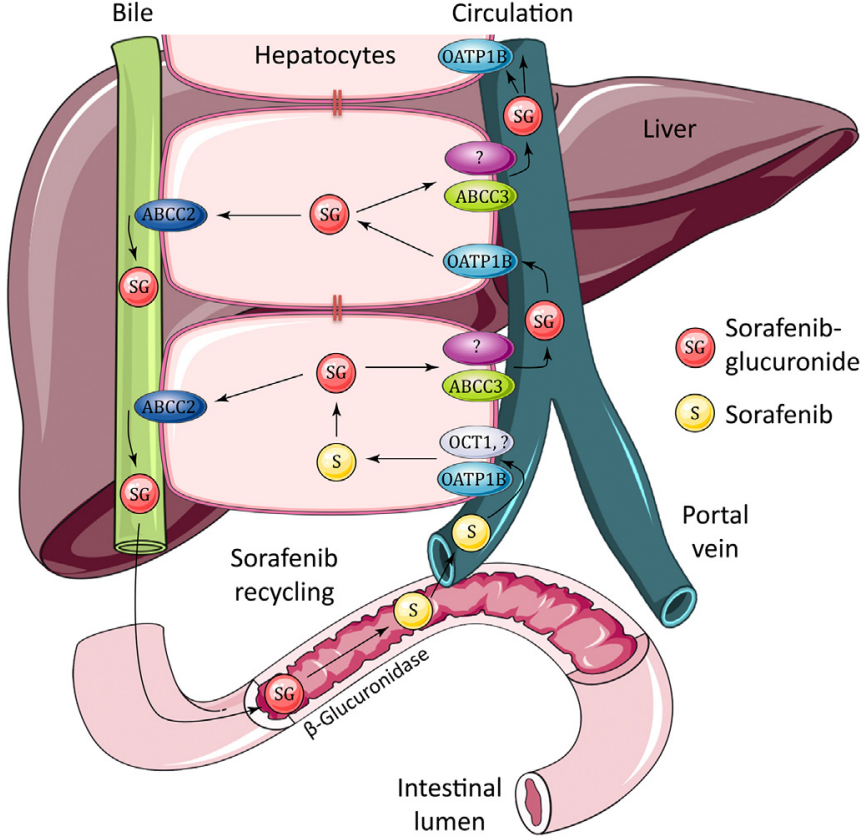

Fig. 4. Schematic diagram of hepatocyte hopping of sorafenib glucuronide and possible recirculation of sorafenib. This schematic presents the likely situation in human liver, as extrapolated from findings in various knockout and humanized mouse strains. After oral administration and intestinal absorption, sorafenib is taken up into the hepatocytes by incompletely defined mechanisms, possibly including OATP1B-type carriers, OCT1, passive diffusion, and perhaps other transporters. Within the hepatocytes, sorafenib undergoes conjugation by UGT1A9 to form sorafenib glucuronide (SG). SG is secreted into the bile primarily by $A B C C 2$, but under physiological conditions a substantial fraction of intracellular SG can also be secreted back into the blood by sinusoidal $\mathrm{ABCC} 3$ and one or more other sinusoidal transport mechanisms. From there SG can be efficiently taken up again by downstream hepatocytes via OATP1B-type carriers (Oatp1a and Oatp1b carriers in mice), resulting in only low SG concentrations reaching the general circulation. This secretion-and-reuptake loop may help to prevent the saturation of ABCC2-mediated biliary SG secretion in hepatocytes positioned upstream within liver lobules. Overall, this can result in efficient biliary elimination and hepatocyte detoxification. Once secreted into the bile, SG enters the intestinal lumen where it can serve as a substrate for bacterial $\beta$-glucuronidases that regenerate sorafenib. This sorafenib can then undergo intestinal absorption, thus reentering the circulation. It has been proposed that this ongoing reabsorption of recirculated SG after hydrolysis to sorafenib contributes to the long-lasting sorafenib plasma levels observed in patients (Hilger et al., 2009; Jain et al., 2011; Vasilyeva et al., 2015). This figure was produced using Servier Medical Art (www.servier.com).

(conjugate) that is strongly affected by hepatocyte hopping, analogous to bilirubin. In order to test this hypothesis, the transport and pharmacokinetics of sorafenib and its glucuronide conjugate were studied in vitro and in a number of single and combination knockout mouse strains, in a collaboration between the groups of S. Baker and A.H. Schinkel (Vasilyeva et al., 2015). In vitro transport assays indicated that sorafenib glucuronide is efficiently transported by mouse, rat, and human Abcc2/ABCC2, but also by human $\mathrm{ABCC} 3$ and ABCC4. Together with the demonstrated transport by Oatp1a/1b and OATP1B1 and OATP1B3, this implies that all transporters that are minimally necessary for the hepatocyte hopping process, are also available for sorafenib glucuronide. In vivo, after oral administration of sorafenib to Abcc2 knockout mice, the plasma AUC of parental sorafenib was hardly altered, but the plasma AUC of sorafenib glucuronide surged from practically undetectable in wild-type mice to more than 200-fold higher levels in the Abcc2 knockout. The sorafenib glucuronide AUC was also at least 5-fold higher than that of parental sorafenib. As expected, there was a dramatic decrease in biliary excretion of sorafenib glucuronide, from $26 \%$ of the administered sorafenib dose over a limited time span in wild-type mice to less than $2.5 \%$ in the Abcc 2 knockout mice. 
Sorafenib glucuronide is thus normally extensively excreted into bile, primarily by Abcc 2 . Accordingly, liver levels of sorafenib glucuronide were 3- to 8-fold increased in the Abcc2 knockout mice (Vasilyeva et al., 2015).

To assess whether or not Abcc 3 and/or Abcc4 were involved in secretion of sorafenib glucuronide from the hepatocyte back into blood, sorafenib and sorafenib glucuronide pharmacokinetics were studied in various single and combination Abcc3, Abcc4, Oatp1a/1b, and $A b c c 2$ knockout strains, after oral sorafenib administration. Single Abcc3, Abcc4, or Abcc3/4 combination knockout strains displayed no significant effect on plasma AUCs of sorafenib or sorafenib glucuronide, but both the Abcc3-deficient strains had an about 2-fold higher liver-to-plasma ratio of sorafenib glucuronide than wild-type and Abcc4 knockout mice, suggesting a role of Abcc3 in limiting hepatic accumulation of sorafenib glucuronide. Indeed, when the Abcc3 deficiency was combined with either the Oatp1a/1b deficiency, or a combined Oatp1a/1b; Abcc2 deficiency, this resulted in, respectively, a 1.9 -fold reduction or a $29 \%$ reduction in plasma AUCs of sorafenib glucuronide. This clearly demonstrated that Abcc3 is substantially involved in the transport of sorafenib glucuronide from the hepatocyte back into blood. Liverto-plasma ratios of sorafenib glucuronide in these combination knockout strains further supported this interpretation. Collectively, these findings lend strong support for the idea that sorafenib glucuronide is also a subject to the process of hepatocyte hopping. The fact that sorafenib glucuronidation capacity in the mouse intestine is very small compared to the hepatic glucuronidation capacity (Zimmerman et al., 2013), further strengthens the interpretation that sorafenib glucuronide predominantly formed in hepatocytes is subject to the hepatocyte hopping process. Fig. 4 shows a schematic diagram of the hepatocyte hopping process for sorafenib glucuronide, with the legend providing more details on the separate steps that sorafenib and sorafenib glucuronide undergo.

It should be noted that, in addition to Abcc3, there must be at least one or more other sinusoidal export processes for sorafenib glucuronide, as the reversal of plasma levels of sorafenib glucuronide was far from complete in the various Abcc 3 combination knockout strains. Based on the results in the Abcc4-deficient strains it seems unlikely that Abcc4 makes a significant contribution, so the nature of the alternative sinusoidal sorafenib glucuronide exporter(s) remains to be elucidated. It could well be that the relative contribution of these alternative export processes increases at the elevated hepatocyte concentrations of sorafenib glucuronide that occur in the Abcc2- and/or Abcc3-deficient mice, for instance due to a high(er) transport $\mathrm{Km}$.

Since the hepatocyte hopping process has now been documented for at least two quite divergent compounds (bilirubin glucuronide and sorafenib glucuronide), it stands to reason that it will also apply to many other compounds that are conjugated in the liver, and that are transport substrates of $A B C C 2, A B C C 3$, and the sinusoidal OATP1 proteins. Given the very broad and often overlapping substrate specificity of all of these transporters, encompassing glucuronide-, glutathione-, and sulfo-conjugates of many endobiotic and xenobiotic compounds, including many drugs, it seems likely that a large number of drugs and other compounds will be affected by the hepatocyte hopping process to a greater or lesser extent. Moreover, additional broad-specificity canalicular and sinusoidal transporters in the liver, such as ABCG2, possibly ABCB11, $A B C C 4$, and OATP2B1, are likely to further contribute to a wideranging impact of the hepatocyte hopping process.

\section{Specificity of OATP1A/1B-mediated drug transport may depend on the cellular context}

In the context of this review it is worth noting that in some cases, for unknown reasons, it appears that transport of OATP substrates is strongly dependent on the cellular context (cell type) in which a specific OATP is expressed. For instance, de Graan et al. (2012) found that docetaxel was not appreciably taken up when OATP1B1 was expressed in Xenopus oocytes, whereas OATP1B3 in the same system readily mediated docetaxel uptake. In contrast, when OATP1B1 and OATP1B3 were expressed in a human embryonic kidney cell line (HEK293), or in a Chinese Hamster Ovary cell line (CHO), both transporters mediated more or less the same amount of docetaxel uptake. Very similar findings were reported for paclitaxel, which was readily transported by OATP1B1 and OATP1B3 expressed in HEK293 and CHO cells, but not by OATP1B1 expressed in Xenopus oocytes, whereas Xenopus-expressed OATP1B3 was active (Nieuweboer et al., 2014). Positive control substrates were readily taken up in all these cases. As described above, subsequent studies in humanized mice indicated that OATP1B1 and OATP1B3 can both transport docetaxel in vivo when expressed in mouse hepatocytes (Iusuf et al., 2015). Similar observations were further made for doxorubicin by Durmus et al. (2014), who found that in vitro in various OATP-transfected HEK293 cells, doxorubicin was not appreciably taken up by human OATP1B1 or OATP1B3, whereas it was taken up by OATP1A2. In contrast, in transgenic humanized mice with overexpression of OATP1B1 or OATP1B3 in the liver, clearly increased liver-to-plasma ratios of doxorubicin were seen, indicating that in mouse hepatocytes these proteins can mediate appreciable doxorubicin uptake. Of note, though, transgenic OATP1A2 was even more effective in mediating doxorubicin uptake into mouse hepatocytes in vivo (Durmus et al., 2014). We therefore cannot exclude that the discrepancy with doxorubicin uptake in the cell lines may in part have been related to expression levels of the transporters. However that may be, the mechanistic background of such discrepancies is as yet a mystery. One can speculate that perhaps in some cases a covalent post-translational modification of an OATP (like phosphorylation or similar process) must occur in order for a certain substrate to be recognized, and that the capacity to make such modifications differs strongly between cell types. There may also be substrate-specific competitive or non-competitive inhibition or stimulation of transport of certain substrates by an OATP by some compounds abundant in some cell types, but not in others. In fact, heterotropic or even homotropic cooperativity phenomena are quite common for multidrug-handling proteins like CYP3A (Ekroos and Sjogren, 2006; Harlow and Halpert, 1998) or multispecific $A B C$ transporters like P-glycoprotein (ABCB1) and ABCC2 (Aller et al., 2009; Bakos et al., 2000; Huisman et al., 2002; Kondratov et al., 2001; Shapiro and Ling, 1998; Zelcer et al., 2003), and this might also apply to the multidrug-handling OATPs. Indeed, a number of compounds have been identified that can stimulate OATP-mediated uptake of some, but not all known substrates of OATP1B1 and/or OATP1B3 (e.g. Gui et al., 2008; Ohnishi et al., 2014; Roth et al., 2011). If the presence of such (endogenous) costimulatory or inhibitory molecules differs between cell types, they may also affect the apparent substrate specificity of OATPs between cell types. Differential pH-dependent uptake of various substrates by OATPs (e.g. Leuthold et al., 2009; Martinez-Becerra et al., 2011; Oostendorp et al., 2009) can perhaps sometimes play a role, and there may be other mechanisms involved that have not been realized yet. Resolving these aspects will present an interesting area for future research into the transport function of OATPs.

\section{Concluding remarks and future perspective}

In the current review we aimed to provide a number of illustrations of how the recent use of knockout and transgenic (humanized) Oatp1a/1b and OATP1A/1B mouse models has helped us to gain insight into the in vivo function of OATP1A/1B transporters, especially with respect to antitumor agents. Apart from 
their pharmacokinetic and toxicological functions, a number of physiological functions of OATP1A/1B proteins have also been elucidated, as well as their interaction with several other transporters, although clearly more work needs to be done in this area. We further touched upon possible pitfalls that can occur during the use of these mouse models, such as the up- (and down-) regulation of a number of carboxylesterase genes in the knockout and transgenic mice. Nonetheless, we believe we can safely state that, when used judiciously, these mouse models can yield a wealth of information on the in vivo physiological functions of OATP1A/1B transporters.

We would like to point out that, while our opinion is that these mouse models are extremely powerful in elucidating principles of in vivo OATP1A/1B functions, one should still use the utmost caution in directly extrapolating from findings in the humanized mouse models to the situation in human patients. An important reason for this is that, even while one may have reproduced the right level of expression and activity of a humanized protein in the right cellular or organ compartment, one is still studying the behavior of this transporter in the complex context of a mouse background. This context may well differ in some relevant aspects for the parameter studied from the context in humans. This caveat should always be borne in mind, and ultimately only careful human studies can point out whether or not the insights and results obtained with the mouse models do also apply fully in humans.

Having said that, we think that there are many additional interesting and promising research lines in cancer and general drug disposition and toxicology, but also in broader physiology, that can be explored with the current set of OATP1A/1B mouse models. Given the now well-established in vivo roles of OATP transporters in the general disposition of many anticancer drugs, of particular interest will also be further investigation of the impact of expression of OATPs in the tumor cells themselves on response to antitumor chemotherapy. Furthermore, the possibility to modulate OATP activity in tumor cells or elsewhere in the body in order to improve chemotherapy response should be investigated. These various possibilities can amongst others be addressed by creating new combinations with existing or newly generated knockout and transgenic mouse lines for other drug transporters and drugmetabolizing enzymes, as well as for certain tumor suppressor- or oncogenes. In other words, the research field of OATP transporters is far from exhausted yet.

\section{Conflicts of interest}

The research group of A.H. Schinkel receives revenue from commercial distribution of some of the mouse models described in this review.

\section{Acknowledgement}

Part of the work in the Schinkel group reviewed in this paper was funded by grant NKI 2007-3764 of the Dutch Cancer Society to A.H. Schinkel.

\section{References}

Abe, T., Unno, M., Onogawa, T., Tokui, T., Kondo, T.N., Nakagomi, R., Adachi, H., Fujiwara, K., Okabe, M., Suzuki, T., Nunoki, K., Sato, E., Kakyo, M., Nishio, T., Sugita, J., Asano, N., Tanemoto, M., Seki, M., Date, F., Ono, K., Kondo, Y., Shiiba, K., Suzuki, M., Ohtani, H., Shimosegawa, T., Iinuma, K., Nagura, H., Ito, S., Matsuno, S., 2001. LST2 , a human liver-specific organic anion transporter, determines methotrexate sensitivity in gastrointestinal cancers. Gastroenterology 120, 1689-1699.

Aller, S.G., Yu, J., Ward, A., Weng, Y., Chittaboina, S., Zhuo, R., Harrell, P.M., Trinh, Y.T., Zhang, Q., Urbatsch, I.L., Chang, G., 2009. Structure of P-glycoprotein reveals a molecular basis for poly-specific drug binding. Science 323, 1718-1722.

Assaraf, Y.G., 2007. Molecular basis of antifolate resistance. Cancer Metastasis Rev. $26,153-181$

Badagnani, I., Castro, R.A., Taylor, T.R., Brett, C.M., Huang, C.C., Stryke, D., Kawamoto, M., Johns, S.J., Ferrin, T.E., Carlson, E.J., Burchard, E.G., Giacomini, K.M., 2006.
Interaction of methotrexate with organic-anion transporting polypeptide $1 \mathrm{~A} 2$ and its genetic variants. J. Pharmacol. Exp. Ther. 318, 521-529.

Baker, S.D., Verweij, J., Cusatis, G.A., van Schaik, R.H., Marsh, S., Orwick, S.J., Franke, R.M., Hu, S., Schuetz, E.G., Lamba, V., Messersmith, W.A., Wolff, A.C., Carducci, M.A., Sparreboom, A., 2009. Pharmacogenetic pathway analysis of docetaxel elimination. Clin. Pharmacol. Ther. 85, 155-163.

Bakos, E., Evers, R., Sinko, E., Varadi, A., Borst, P., Sarkadi, B., 2000. Interactions of the human multidrug resistance proteins MRP1 and MRP2 with organic anions. Mol. Pharmacol. 57, 760-768.

Bram, E.E., Adar, Y., Mesika, N., Sabisz, M., Skladanowski, A., Assaraf, Y.G., 2009. Structural determinants of imidazoacridinones facilitating antitumor activity are crucial for substrate recognition by ABCG2. Mol. Pharmacol. 75, 1149-1159.

Cheng, X., Maher, J., Chen, C., Klaassen, C.D., 2005. Tissue distribution and ontogeny of mouse organic anion transporting polypeptides (Oatps). Drug Metab. Dispos. 33, 1062-1073.

Cortes-Funes, H., Coronado, C., 2007. Role of anthracyclines in the era of targeted therapy. Cardiovasc. Toxicol. 7, 56-60.

Cui, Y., Konig, J., Nies, A.T., Pfannschmidt, M., Hergt, M., Franke, W.W., Alt, W., Moll, R. Keppler, D., 2003. Detection of the human organic anion transporters SLC21A6 (OATP2) and SLC21A8 (OATP8) in liver and hepatocellular carcinoma. Lab. Invest. 83, 527-538.

de Graan, A.J., Lancaster, C.S., Obaidat, A., Hagenbuch, B., Elens, L., Friberg, L.E., de Bruijn, P., Hu, S., Gibson, A.A., Bruun, G.H., Corydon, T.J., Mikkelsen, T.S., Walker, A.L., Du, G., Loos, W.J., van Schaik, R.H., Baker, S.D., Mathijssen, R.H., Sparreboom, A., 2012. Influence of polymorphic OATP1B-type carriers on the disposition of docetaxel. Clin. Cancer Res. 18, 4433-4440.

Drozdzik, M., Groer, C., Penski, J., Lapczuk, J., Ostrowski, M., Lai, Y., Prasad, B., Unadkat, J.D., Siegmund, W., Oswald, S., 2014. Protein abundance of clinically relevant multidrug transporters along the entire length of the human intestine. Mol. Pharm. 11, 3547-3555.

Druker, B.J., Talpaz, M., Resta, D.J., Peng, B., Buchdunger, E., Ford, J.M., Lydon, N.B. Kantarjian, H., Capdeville, R., Ohno-Jones, S., Sawyers, C.L., 2001. Efficacy and safety of a specific inhibitor of the BCR-ABL tyrosine kinase in chronic myeloid leukemia. N. Engl. J. Med. 344, 1031-1037.

Duran, G.E., Wang, Y.C., Francisco, E.B., Rose, J.C., Martinez, F.J., Coller, J., Brassard, D., Vrignaud, P., Sikic, B.I., 2015. Mechanisms of resistance to cabazitaxel. Mol. Cancer Ther. 14, 193-201.

Durmus, S., Lozano-Mena, G., van Esch, A., Wagenaar, E., van Tellingen, O. Schinkel, A.H., 2015. Preclinical mouse models to study human OATP1B1- and OATP1B3-mediated drug-drug interactions in vivo. Mol. Pharm. 12, 42594269.

Durmus, S., Naik, J., Buil, L., Wagenaar, E., van Tellingen, O., Schinkel, A.H., 2014. In vivo disposition of doxorubicin is affected by mouse Oatp $1 \mathrm{a} / 1 \mathrm{~b}$ and human OATP1A/1B transporters. Int. J. Cancer. 135, 1700-1710.

Ekroos, M., Sjogren, T., 2006. Structural basis for ligand promiscuity in cytochrome P450 3A4. Proc. Natl. Acad. Sci. U. S. A. 103, 13682-13687.

Figg 2nd, W.D., Figg, W.D., 2010. Cabazitaxel: filling one of the gaps in the treatment of prostate cancer. Cancer Biol. Ther. 10, 1233-1234

Franke, R.M., Scherkenbach, L.A., Sparreboom, A., 2009. Pharmacogenetics of the organic anion transporting polypeptide 1 A2. Pharmacogenomics 10, 339-344.

Gao, B., Hagenbuch, B., Kullak-Ublick, G.A., Benke, D., Aguzzi, A., Meier, P.J., 2000. Organic anion-transporting polypeptides mediate transport of opioid peptides across blood-brain barrier. J. Pharmacol. Exp. Ther. 294, 73-79.

Gewirtz, D.A., 1999. A critical evaluation of the mechanisms of action proposed for the antitumor effects of the anthracycline antibiotics adriamycin and daunorubicin. Biochem. Pharmacol. 57, 727-741.

Glaeser, H., Bailey, D.G., Dresser, G.K., Gregor, J.C., Schwarz, U.I., McGrath, J.S., Jolicoeur, E., Lee, W., Leake, B.F., Tirona, R.G., Kim, R.B., 2007. Intestinal drug transporter expression and the impact of grapefruit juice in humans. Clin. Pharmacol. Ther. 81, 362-370.

Gligorov, J., Lotz, J.P., 2004. Preclinical pharmacology of the taxanes: implications of the differences. Oncologist 9 (Suppl. 2), 3-8.

Gonen, N., Assaraf, Y.G., 2012. Antifolates in cancer therapy: structure, activity and mechanisms of drug resistance. Drug Resist. Updat. 15, 183-210.

Gong, I.Y., Kim, R.B., 2013. Impact of genetic variation in OATP transporters to drug disposition and response. Drug Metab. Pharmacokinet. 28, 4-18.

Gong, L., Aranibar, N., Han, Y.H., Zhang, Y., Lecureux, L., Bhaskaran, V., Khandelwal, P., Klaassen, C.D., Lehman-McKeeman, L.D., 2011. Characterization of organic anion-transporting polypeptide (Oatp) $1 \mathrm{a} 1$ and 1a4 null mice reveals altered transport function and urinary metabolomic profiles. Toxicol. Sci. 122, 587-597.

Grenier, M.A., Lipshultz, S.E., 1998. Epidemiology of anthracycline cardiotoxicity in children and adults. Semin. Oncol. 25, 72-85.

Gui, C., Miao, Y., Thompson, L., Wahlgren, B., Mock, M., Stieger, B., Hagenbuch, B. 2008. Effect of pregnane $\mathrm{X}$ receptor ligands on transport mediated by human OATP1B1 and OATP1B3. Eur. J. Pharmacol. 584, 57-65.

Han, J.Y., Lim, H.S., Shin, E.S., Yoo, Y.K., Park, Y.H., Lee, J.E., Kim, H.T., Lee, J.S., 2008 Influence of the organic anion-transporting polypeptide 1B1 (OATP1B1) polymorphisms on irinotecan-pharmacokinetics and clinical outcome of patients with advanced non-small cell lung cancer. Lung Cancer 59, 69-75.

Harlow, G.R., Halpert, J.R., 1998. Analysis of human cytochrome P450 3A4 cooperativity: construction and characterization of a site-directed mutant that displays hyperbolic steroid hydroxylation kinetics. Proc. Natl. Acad. Sci. U. S. A. 95, 6636-6641

Higgins, J.W., Bao, J.Q., Ke, A.B., Manro, J.R., Fallon, J.K., Smith, P.C., ZamekGliszczynski, M.J., 2014. Utility of Oatp1a/1b-knockout and OATP1B1/3 humanized mice in the study of OATP-mediated pharmacokinetics and tissue 
distribution: case studies with pravastatin, atorvastatin, simvastatin, and carboxydichlorofluorescein. Drug Metab. Dispos. 42, 182-192.

Hilger, R.A., Richly, H., Grubert, M., Kredtke, S., Thyssen, D., Eberhardt, W., Hense J., Schuler, M., Scheulen, M.E., 2009. Pharmacokinetics of sorafenib in patients with renal impairment undergoing hemodialysis. Int. J. Clin. Pharmacol. Ther 47, 61-64.

Holmes, R.S., Wright, M.W., Laulederkind, S.J., Cox, L.A., Hosokawa, M., Imai, T Ishibashi, S., Lehner, R., Miyazaki, M., Perkins, E.J., Potter, P.M., Redinbo, M.R Robert, J., Satoh, T., Yamashita, T., Yan, B., Yokoi, T., Zechner, R., Maltais, L.J., 2010. Recommended nomenclature for five mammalian carboxylesterase gene families: human, mouse, and rat genes and proteins. Mamm. Genome 21, 427-441.

Hu, S., Franke, R.M., Filipski, K.K., Hu, C., Orwick, S.J., de Bruijn, E.A., Burger, H. Baker, S.D., Sparreboom, A., 2008. Interaction of imatinib with human organic ion carriers. Clin. Cancer Res. 14, 3141-3148.

Hu, S., Mathijssen, R.H., de Bruijn, P., Baker, S.D., Sparreboom, A., 2014. Inhibition of OATP1B1 by tyrosine kinase inhibitors: in vitro-in vivo correlations. Br. J. Cancer $110,894-898$.

Huisman, M.T., Smit, J.W., Crommentuyn, K.M., Zelcer, N., Wiltshire, H.R., Beijnen, J.H., Schinkel, A.H., 2002. Multidrug resistance protein 2 (MRP2) transports HIV protease inhibitors, and transport can be enhanced by other drugs. AIDS 16 2295-2301.

Innocenti, F., Kroetz, D.L., Schuetz, E., Dolan, M.E., Ramirez, J., Relling, M., Chen, P., Das, S., Rosner, G.L., Ratain, M.J., 2009. Comprehensive pharmacogenetic analysis of irinotecan neutropenia and pharmacokinetics. J. Clin. Oncol. 27, 2604-2614.

Iusuf, D., Hendrikx, J.J., van Esch, A., van de Steeg, E., Wagenaar, E., Rosing, H., Beijnen, J.H., Schinkel, A.H., 2015. Human OATP1B1, OATP1B3 and OATP1A2 can mediate the in vivo uptake and clearance of docetaxel. Int. J. Cancer 136, 225-233.

Iusuf, D., Ludwig, M., Elbatsh, A., van Esch, A., van de Steeg, E., Wagenaar, E., van der Valk, M., Lin, F., van Tellingen, O., Schinkel, A.H., 2014. OATP1A/1B transporters affect irinotecan and $\mathrm{SN}-38$ pharmacokinetics and carboxylesterase expression in knockout and humanized transgenic mice. Mol. Cancer Ther. 13, 492-503.

Iusuf, D., Sparidans, R.W., van Esch, A., Hobbs, M., Kenworthy, K.E., van de Steeg, E. Wagenaar, E., Beijnen, J.H., Schinkel, A.H., 2012a. Organic anion-transporting polypeptides 1a/1b control the hepatic uptake of pravastatin in mice. Mol Pharm. 9, 2497-2504.

Iusuf, D., van de Steeg, E., Schinkel, A.H., 2012b. Functions of OATP1A and 1B transporters in vivo: insights from mouse models. Trends Pharmacol. Sci. 33, 100-108

Iusuf, D., van de Steeg, E., Schinkel, A.H., 2012c. Hepatocyte hopping of OATP1B substrates contributes to efficient hepatic detoxification. Clin. Pharmacol. Ther. 92, 559-562.

Iusuf, D., van Esch, A., Hobbs, M., Taylor, M., Kenworthy, K.E., van de Steeg, E., Wagenaar, E., Schinkel, A.H., 2013. Murine Oatp1a/1b uptake transporters control rosuvastatin systemic exposure without affecting its apparent liver exposure. Mol. Pharmacol. 83, 919-929.

Jain, L., Woo, S., Gardner, E.R., Dahut, W.L., Kohn, E.C., Kummar, S., Mould, D.R., Giaccone, G., Yarchoan, R., Venitz, J., Figg, W.D., 2011. Population pharmacokinetic analysis of sorafenib in patients with solid tumours. Br. J. Clin. Pharmacol. 72 294-305

Kathawala, R.J., Wang, Y.J., Shukla, S., Zhang, Y.K., Alqahtani, S., Kaddoumi, A., Ambudkar, S.V., Ashby Jr., C.R., Chen, Z.S., 2015. ATP-binding cassette subfamily $B$ member 1 (ABCB1) and subfamily C member 10 (ABCC10) are not primary resistance factors for cabazitaxel. Chin. J. Cancer 34, 115-120.

Kondratov, R.V., Komarov, P.G., Becker, Y., Ewenson, A., Gudkov, A.V., 2001. Small molecules that dramatically alter multidrug resistance phenotype by modulating the substrate specificity of P-glycoprotein. Proc. Natl. Acad. Sci. U. S. A. 98 $14078-14083$.

Konig, J., Muller, F., Fromm, M.F., 2013. Transporters and drug-drug interactions: important determinants of drug disposition and effects. Pharmacol. Rev. 65 944-966.

Koolen, S.L., Beijnen, J.H., Schellens, J.H., 2010. Intravenous-to-oral switch in anticancer chemotherapy: a focus on docetaxel and paclitaxel. Clin. Pharmacol. Ther $87,126-129$

Lagas, J.S., Damen, C.W., van Waterschoot, R.A., Iusuf, D., Beijnen, J.H., Schinkel, A.H 2012. P-glycoprotein, multidrug-resistance associated protein 2, Cyp3a, and carboxylesterase affect the oral availability and metabolism of vinorelbine. Mol. Pharmacol. 82, 636-644.

Lancaster, C.S., Sprowl, J.A., Walker, A.L., Hu, S., Gibson, A.A., Sparreboom, A., 2013. Modulation of OATP1B-type transporter function alters cellular uptake and disposition of platinum chemotherapeutics. Mol. Cancer Ther. 12, 1537-1544.

Lee, H.H., Leake, B.F., Teft, W., Tirona, R.G., Kim, R.B., Ho, R.H., 2015. Contribution of hepatic organic anion-transporting polypeptides to docetaxel uptake and clearance. Mol. Cancer Ther. 14, 994-1003.

Lee, W., Glaeser, H., Smith, L.H., Roberts, R.L., Moeckel, G.W., Gervasini, G., Leake, B.F. Kim, R.B., 2005. Polymorphisms in human organic anion-transporting polypeptide 1A2 (OATP1A2): implications for altered drug disposition and central nervous system drug entry. J. Biol. Chem. 280, 9610-9617.

Leuthold, S., Hagenbuch, B., Mohebbi, N., Wagner, C.A., Meier, P.J., Stieger, B. 2009. Mechanisms of $\mathrm{pH}$-gradient driven transport mediated by organic anion polypeptide transporters. Am. J. Physiol. Cell Physiol. 296, C570-C582.

Lu, H., Choudhuri, S., Ogura, K., Csanaky, I.L., Lei, X., Cheng, X., Song, P.Z., Klaassen, C.D., 2008. Characterization of organic anion transporting polypeptide 1b2-nul mice: essential role in hepatic uptake/toxicity of phalloidin and microcystin-LR Toxicol. Sci. 103, 35-45

Martinez-Becerra, P., Briz, O., Romero, M.R., Macias, R.I., Perez, M.J., Sancho-Mateo, C. Lostao, M.P., Fernandez-Abalos, J.M., Marin, J.J. 2011. Further charac terization of the electrogenicity and $\mathrm{pH}$ sensitivity of the human organic anion-transporting polypeptides OATP1B1 and OATP1B3. Mol. Pharmacol. 79 596-607.

Mathijssen, R.H., Loos, W.J., Verweij, J., Sparreboom, A., 2002. Pharmacology of topoisomerase I inhibitors irinotecan (CPT-11) and topotecan. Curr. Cancer Drug Targets 2, 103-123.

Minotti, G., Menna, P., Salvatorelli, E., Cairo, G., Gianni, L., 2004. Anthracyclines: molecular advances and pharmacologic developments in antitumor activity and cardiotoxicity. Pharmacol. Rev. 56, 185-229.

Monks, N.R., Liu, S., Xu, Y., Yu, H., Bendelow, A.S., Moscow, J.A., 2007. Potent cytotoxicity of the phosphatase inhibitor microcystin LR and microcystin analogues in OATP1B1- and OATP1B3-expressing HeL a cells. Mol. Cancer Ther. 6, 587-598.

Muto, M., Onogawa, T., Suzuki, T., Ishida, T., Rikiyama, T., Katayose, Y., Ohuchi, N., Sasano, H., Abe, T., Unno, M., 2007. Human liver-specific organic anion transporter-2 is a potent prognostic factor for human breast carcinoma. Cancer Sci. 98, 1570-1576

Nakanishi, T., Tamai, I., 2012. Genetic polymorphisms of OATP transporters and their impact on intestinal absorption and hepatic disposition of drugs. Drug Metab. Pharmacokinet. 27, 106-121.

Nakanishi, T., Tamai, I., 2014. Putative roles of organic anion transporting polypeptides (OATPs) in cell survival and progression of human cancers. Biopharm. Drug Dispos. 35, 463-484.

Niemi, M., Pasanen, M.K., Neuvonen, P.J., 2011. Organic anion transporting polypeptide 1B1: a genetically polymorphic transporter of major importance for hepatic drug uptake. Pharmacol. Rev. 63, 157-181.

Nieuweboer, A.J., Hu, S., Gui, C., Hagenbuch, B., Ghobadi Moghaddam-Helmantel I.M., Gibson, A.A., de Bruijn, P., Mathijssen, R.H., Sparreboom, A., 2014. Influence of drug formulation on OATP1B-mediated transport of paclitaxel. Cancer Res. 74, 3137-3145.

Nozawa, T., Minami, H., Sugiura, S., Tsuji, A., Tamai, I., 2005. Role of organic anion transporter OATP1B1 (OATP-C) in hepatic uptake of irinotecan and its active metabolite, 7-ethyl-10-hydroxycamptothecin: in vitro evidence and effect of single nucleotide polymorphisms. Drug Metab. Dispos. 33, 434-439.

Obaidat, A., Roth, M., Hagenbuch, B., 2012. The expression and function of organic anion transporting polypeptides in normal tissues and in cancer. Annu. Rev. Pharmacol. Toxicol. 52, 135-151.

Ohnishi, S., Hays, A., Hagenbuch, B., 2014. Cysteine scanning mutagenesis of transmembrane domain 10 in organic anion transporting polypeptide 1B1. Biochemistry $53,2261-2270$

Okabe, M., Unno, M., Harigae, $\mathrm{H}$., Kaku, M., Okitsu, Y Sasaki, T., Mizoi, T., Shiiba, K. Takanaga, H., Terasaki, T., Matsuno, S., Sasaki, I., Ito, S., Abe, T., 2005. Characterization of the organic cation transporter SLC22A16: a doxorubicin importer Biochem. Biophys. Res. Commun. 333, 754-762.

Oostendorp, R.L., van de Steeg, E., van der Kruijssen, C.M., Beijnen, J.H., Kenworthy, K.E., Schinkel, A.H., Schellens, J.H., 2009. Organic anion-transporting polypeptide $1 \mathrm{~B} 1$ mediates transport of Gimatecan and BNP1350 and can be inhibited by several classic ATP-binding cassette (ABC) B1 and/or ABCG2 inhibitors. Drug Metab. Dispos. 37, 917-923.

Ose, A., Kusuhara, H., Endo, C., Tohyama, K., Miyajima, M., Kitamura, S., Sugiyama, Y., 2010. Functional characterization of mouse organic anion transporting peptide $1 \mathrm{a} 4$ in the uptake and efflux of drugs across the blood-brain barrier. Drug Metab. Dispos. 38, 168-176.

Paller, C.J., Antonarakis, E.S., 2011. Cabazitaxel: a novel second-line treatment for metastatic castration-resistant prostate cancer. Drug Des. Dev. Ther. 5 117-124.

Roth, M., Araya, J.J., Timmermann, B.N., Hagenbuch, B., 2011. Isolation of modulators of the liver-specific organic anion-transporting polypeptides (OATPs) $1 \mathrm{~B} 1$ and $1 \mathrm{~B} 3$ from Rollinia emarginata Schlecht (Annonaceae). J. Pharmacol. Exp. Ther. 339, 624-632

Rowinsky, E.K., Donehower, R.C., 1995. Paclitaxel (taxol). N. Engl. J. Med. 332 1004-1014

Salphati, L., Chu, X., Chen, L., Prasad, B., Dallas, S., Evers, R., Mamaril-Fishman, D., Geier, E.G., Kehler, J., Kunta, J., Mezler, M., Laplanche, L., Pang, J., Rode, A., Soars, M.G., Unadkat, J.D., van Waterschoot, R.A., Yabut, J., Schinkel, A.H., Scheer, N. 2014. Evaluation of organic anion transporting polypeptide 1B1 and $1 \mathrm{~B} 3$ humanized mice as a translational model to study the pharmacokinetics of statins. Drug Metab. Dispos. 42, 1301-1313.

Sasaki, M., Suzuki, H., Aoki, J., Ito, K., Meier, P.J., Sugiyama, Y., 2004. Prediction of in vivo biliary clearance from the in vitro transcellular transport of organic anions across a double-transfected Madin-Darby canine kidney II monolayer expressing both rat organic anion transporting polypeptide 4 and multidrug resistance associated protein 2 . Mol. Pharmacol. 66, 450-459.

Shapiro, A.B., Ling, V., 1998. The mechanism of ATP-dependent multidrug transport by P-glycoprotein. Acta Physiol. Scand. Suppl. 643, 227-234.

Shitara, Y., Maeda, K., Ikejiri, K. Yoshida, K, Horie, T., Sugiyama, Y, 2013. Clinica significance of organic anion transporting polypeptides (OATPs) in drug disposition: their roles in hepatic clearance and intestinal absorption. Biopharm. Drug Dispos. 34, 45-78.

Sissung, T.M., Reece, K.M., Spencer, S., Figg, W.D., 2012. Contribution of the OATP1B subfamily to cancer biology and treatment. Clin. Pharmacol. Ther. 92, 658660

Smith, N.F., Figg, W.D., Sparreboom, A., 2006. Pharmacogenetics of irinotecan metabolism and transport: an update. Toxicol. In Vitro 20, 163-175.

Sparreboom, A., Mathijssen, R.H., 2014. Hepatic uptake transporters and docetaxe disposition in mice-letter. Clin. Cancer Res. 20, p4167.

Sprowl, J.A., Sparreboom, A., 2014. Uptake carriers and oncology drug safety. Drug Metab. Dispos. 42, 611-622. 
Stangier, J., Su, C.A., Roth, W., 2000. Pharmacokinetics of orally and intravenously administered telmisartan in healthy young and elderly volunteers and in hypertensive patients. J. Int. Med. Res. 28, 149-167.

Stieger, B., Hagenbuch, B., 2014. Organic anion-transporting polypeptides. Curr. Top. Membr. 73, 205-232.

Svoboda, M., Wlcek, K., Taferner, B., Hering, S., Stieger, B., Tong, D., Zeillinger, R., Thalhammer, T., Jager, W., 2011. Expression of organic anion-transporting polypeptides 1B1 and 1B3 in ovarian cancer cells: relevance for paclitaxel transport. Biomed. Pharmacother. 65, 417-426.

Takane, H., Kawamoto, K., Sasaki, T., Moriki, K., Moriki, K., Kitano, H., Higuchi, S., Otsubo, K., Ieiri, I., 2009. Life-threatening toxicities in a patient with UGT1A1*6/*28 and SLCO1B1*15/*15 genotypes after irinotecan-based chemotherapy. Cancer Chemother. Pharmacol. 63, 1165-1169.

Tang, S.C., Hendrikx, J.J., Beijnen, J.H., Schinkel, A.H., 2013. Genetically modified mouse models for oral drug absorption and disposition. Curr. Opin. Pharmacol. $13,853-858$

Tang, S.C., Kort, A., Cheung, K.L., Rosing, H., Fukami, T., Durmus, S., Wagenaar, E., Hendrikx, J.J., Nakajima, M., van Vlijmen, B.J., Beijnen, J.H., Schinkel, A.H., 2015 P-glycoprotein, CYP3A, and plasma carboxylesterase determine brain disposition and oral availability of the novel taxane cabazitaxel (jevtana) in mice. Mol. Pharm. 12, 3714-3723.

Tang, S.C., Sparidans, R.W., Cheung, K.L., Fukami, T., Durmus, S., Wagenaar, E., Yokoi, T., van Vlijmen, B.J., Beijnen, J.H., Schinkel, A.H., 2014. P-glycoprotein, CYP3A, and plasma carboxylesterase determine brain and blood disposition of the mTOR Inhibitor everolimus (Afinitor) in mice. Clin. Cancer Res. 20, 3133-3145.

Thakkar, N., Lockhart, A.C., Lee, W., 2015. Role of organic anion-transporting polypeptides (OATPs) in cancer therapy. AAPS J. 17, 535-545.

Trevino, L.R., Shimasaki, N., Yang, W., Panetta, J.C., Cheng, C., Pei, D., Chan, D. Sparreboom, A., Giacomini, K.M., Pui, C.H., Evans, W.E., Relling, M.V., 2009 Germline genetic variation in an organic anion transporter polypeptide associated with methotrexate pharmacokinetics and clinical effects. J. Clin. Oncol. 27. 5972-5978.

van de Steeg, E., Stranecky, V., Hartmannova, H., Noskova, L., Hrebicek, M., Wagenaar, E., van Esch, A., de Waart, D.R., Oude Elferink, R.P., Kenworthy, K.E., Sticova, E., al-Edreesi, M., Knisely, A.S., Kmoch, S., Jirsa, M., Schinkel, A.H., 2012. Complete OATP1B1 and OATP1B3 deficiency causes human Rotor syndrome by interrupting conjugated bilirubin reuptake into the liver. J. Clin. Invest. 122, 519-528.

van de Steeg, E., van der Kruijssen, C.M., Wagenaar, E., Burggraaff, J.E., Mesman, E., Kenworthy, K.E., Schinkel, A.H., 2009. Methotrexate pharmacokinetics in transgenic mice with liver-specific expression of human organic anion-transporting polypeptide 1B1 (SLCO1B1). Drug Metab. Dispos. 37, 277-281.

van de Steeg, E., van Esch, A., Wagenaar, E., Kenworthy, K.E., Schinkel, A.H., 2013. Influence of human OATP1B1, OATP1B3, and OATP1A2 on the pharmacokinetics of methotrexate and paclitaxel in humanized transgenic mice. Clin. Cancer Res. $19,821-832$.

Van de Steeg, E., van Esch, A., Wagenaar, E., van der Kruijssen, C.M., van Tellingen, O., Kenworthy, K.E., Schinkel, A.H., 2011. High impact of Oatp1a/1b transporters on in vivo disposition of the hydrophobic anticancer drug paclitaxel. Clin. Cancer Res. 17, 294-301.

van de Steeg, E., Wagenaar, E., van der Kruijssen, C.M., Burggraaff, J.E., de Waart, D.R. Elferink, R.P., Kenworthy, K.E., Schinkel, A.H., 2010. Organic anion transporting polypeptide 1a/1b-knockout mice provide insights into hepatic handling of bilirubin, bile acids, and drugs. J. Clin. Invest. 120, 2942-2952.

van Outryve, S., Schrijvers, D., van den Brande, J., Wilmes, P., Bogers, J., van Marck, E., Vermorken, J.B., 2002. Methotrexate-associated liver toxicity in a patient with breast cancer: case report and literature review. Neth. J. Med. 60, 216-222.

Vasilyeva, A., Durmus, S., Li, L., Wagenaar, E., Hu, S., Gibson, A.A., Panetta, J.C., Mani, S., Sparreboom, A., Baker, S.D., Schinkel, A.H., 2015. Hepatocellular shuttling and recirculation of sorafenib-glucuronide is dependent on Abcc2, Abcc3, and Oatp1a/1b. Cancer Res. 75, 2729-2736.

Watanabe, T., Kusuhara, H., Maeda, K., Shitara, Y., Sugiyama, Y., 2009. Physiologically based pharmacokinetic modeling to predict transporter-mediated clearance and distribution of pravastatin in humans. J. Pharmacol. Exp. Ther. 328, 652-662.

Watanabe, T., Kusuhara, H., Sugiyama, Y., 2010. Application of physiologically based pharmacokinetic modeling and clearance concept to drugs showing transporter-mediated distribution and clearance in humans. J. Pharmacokinet. Pharmacodyn. 37, 575-590.

Wessels, J.A., Huizinga, T.W., Guchelaar, H.J., 2008. Recent insights in the pharmacological actions of methotrexate in the treatment of rheumatoid arthritis. Rheumatology (Oxf.) 47, 249-255.

Wu, P., Nielsen, T.E., Clausen, M.H., 2015. FDA-approved small-molecule kinase inhibitors. Trends Pharmacol. Sci. 36, 422-439.

Xiang, X., Jada, S.R., Li, H.H., Fan, L., Tham, L.S., Wong, C.I., Lee, S.C., Lim, R., Zhou, Q.Y. Goh, B.C., Tan, E.H., Chowbay, B., 2006. Pharmacogenetics of SLCO1B1 gene and the impact of *1b and *15 haplotypes on irinotecan disposition in Asian cancer patients. Pharmacogenet. Genomics 16, 683-691.

Yamaguchi, H., Kobayashi, M., Okada, M., Takeuchi, T., Unno, M., Abe, T., Goto, J., Hishinuma, T., Mano, N., 2008. Rapid screening of antineoplastic candidates for the human organic anion transporter OATP1B3 substrates using fluorescent probes. Cancer Lett. 260, 163-169.

Zaher, H., Meyer zu Schwabedissen, H.E., Tirona, R.G., Cox, M.L., Obert, L.A., Agrawal, N., Palandra, J., Stock, J.L., Kim, R.B., Ware, J.A., 2008. Targeted disruption of murine organic anion-transporting polypeptide 1b2 (Oatp1b2/Slco1b2) significantly alters disposition of prototypical drug substrates pravastatin and rifampin. Mol. Pharmacol. 74, 320-329.

Zelcer, N., Huisman, M.T., Reid, G., Wielinga, P., Breedveld, P., Kuil, A., Knipscheer, P. Schellens, J.H., Schinkel, A.H., Borst, P., 2003. Evidence for two interacting ligand binding sites in human multidrug resistance protein 2 (ATP binding cassette C2) J. Biol. Chem. 278, 23538-23544.

Zhou, S., Chan, E., Duan, W., Huang, M., Chen, Y.Z., 2005. Drug bioactivation, covalent binding to target proteins and toxicity relevance. Drug Metab. Rev. 37, 41-213.

Zimmerman, E.I., Hu, S., Roberts, J.L., Gibson, A.A., Orwick, S.J., Li, L., Sparreboom, A. Baker, S.D., 2013. Contribution of OATP1B1 and OATP1B3 to the disposition of sorafenib and sorafenib-glucuronide. Clin. Cancer Res. 19, 1458-1466. 